US Army Corps

of Engineers ${ }_{\circledast}$

Engineer Research and

Development Center

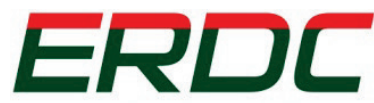

INNOVATIVE SOLUTIONS

for a safer, better world

\title{
Inclement Weather Crater Repair Tool Kit
}

Haley P. Bell and Jeb S. Tingle

November 2017
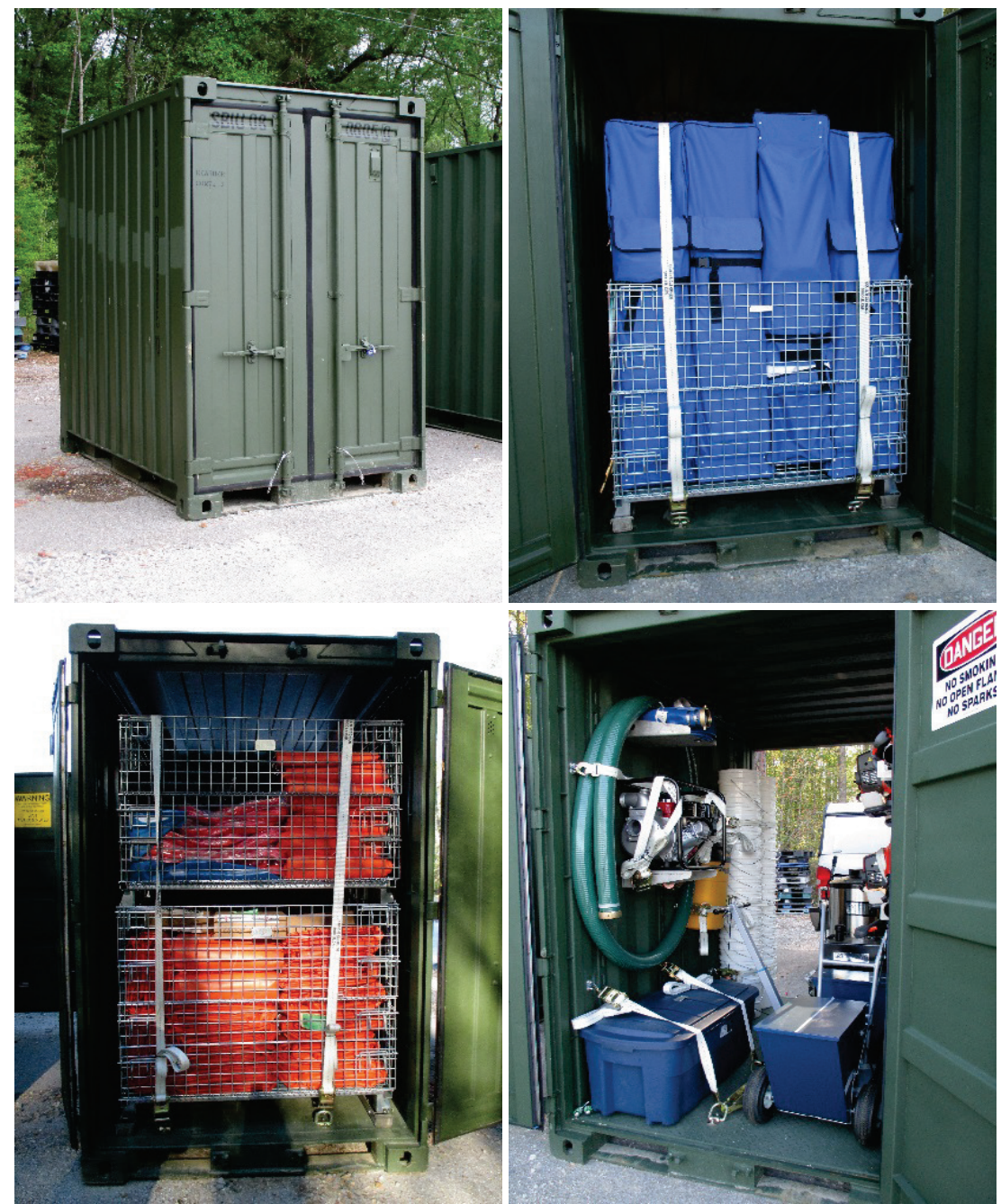
The U.S. Army Engineer Research and Development Center (ERDC) solves the nation's toughest engineering and environmental challenges. ERDC develops innovative solutions in civil and military engineering, geospatial sciences, water resources, and environmental sciences for the Army, the Department of Defense, civilian agencies, and our nation's public good. Find out more at www.erdc.usace.army.mil.

To search for other technical reports published by ERDC, visit the ERDC online library at http://acwc.sdp.sirsi.net/client/default. 
ERDC/GSL TR-17-26

November 2017

\section{Inclement Weather Crater Repair Tool Kit}

Haley P. Bell and Jeb S. Tingle

Geotechnical and Structures Laboratory

U.S. Army Engineer Research and Development Center

3909 Halls Ferry Road

Vicksburg, MS 39180-6199

Final report

Approved for public release; distribution is unlimited.

Prepared for Headquarters, U.S. Air Force Civil Engineer Center

Tyndall Air Force Base, FL 32403-5319

Under Project Number 333159 


\section{Abstract}

During the period October 2015 through May 2016, the U.S. Army Engineer Research and Development Center (ERDC) in Vicksburg, MS, worked to develop a prototype tool kit comprised of equipment and materials needed to repair concrete and asphalt craters on airfield pavements during times of inclement weather. The tool kit is used to supplement an existing crater repair tool kit developed for fair weather scenarios. The items selected for inclusion in the kit were based on previous research and evaluation of crater repair methods and during specific full-scale inclement weather crater repair experiments. This report presents a summary of the research conducted to help determine the prototype Inclement Weather Crater Repair Tool Kit contents and also presents the specific details of the kit, including inventory and drawings.

DISCLAIMER: The contents of this report are not to be used for advertising, publication, or promotional purposes. Citation of trade names does not constitute an official endorsement or approval of the use of such commercial products. All product names and trademarks cited are the property of their respective owners. The findings of this report are not to be construed as an official Department of the Army position unless so designated by other authorized documents. 


\section{Contents}

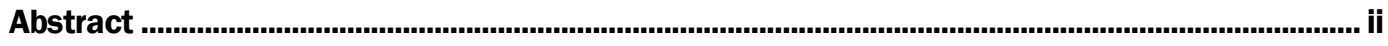

Figures and Tables.......................................................................................................................

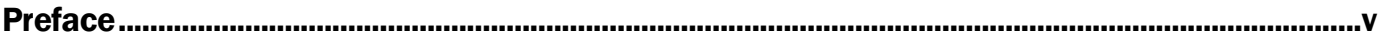

Unit Conversion Factors .....................................................................................................................vi

1 Introduction .............................................................................................................................. 1

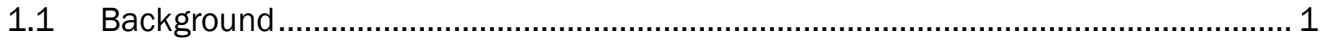

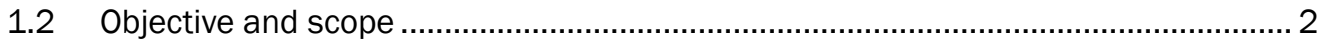

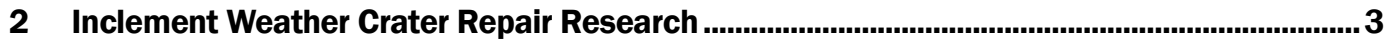

2.1 Crater repair process ...................................................................................... 3

2.2 Cold weather crater repair testing ...................................................................... 9

2.3 Wet weather crater repair testing ............................................................... 10

3 Inclement Weather Crater Repair Tool Kit Contents ........................................................13

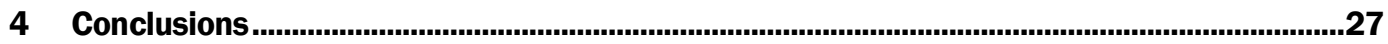

References ...............................................................................................................................................28

Appendix: Inclement Weather ADR Crater Repair Prototype Tool Kit Design Drawings.............29

Report Documentation Page 


\section{Figures and Tables}

\section{Figures}

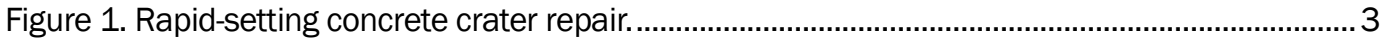

Figure 2. Trailer hauling super sacks of cementitious material.......................................................... 4

Figure 3. Crater profile measuring using stanchions. …………………………………………... 5

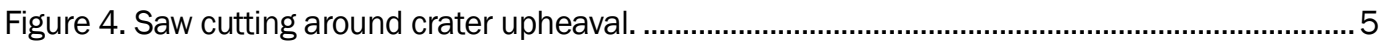

Figure 5. Placing flowable fill backfill using the dry method. ................................................................ 6

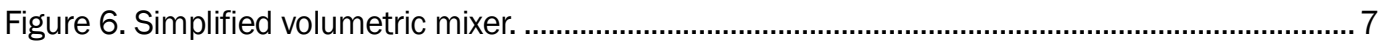

Figure 7. Crater repair with Rapid Set Concrete Mix ${ }^{\circledR}$ using the volumetric mixer. ................................ 8

Figure 8. Calibrated sprinkler system used for wet weather crater repair tests.................................11

Figure 9. Corrugated steel quadcons. ............................................................................................

Figure 10. Quadcon connecting couplers.................................................................................15

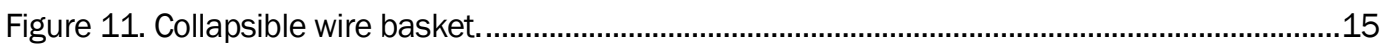

Figure 12. 50-gal plastic tote......................................................................................................16

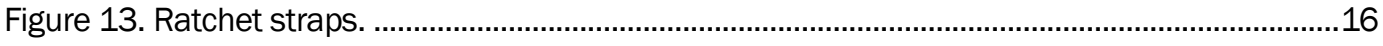

Figure 14. 12,000-lb (left) and 1,000-lb (right) surface mount rope rings........................................17

Figure 15. Metal label attached to wire basket. …………............................................................17

Figure 16. Dry-line marker, No. 10 sieve, 5-gal bucket with lid, and scoop. ....................................18

Figure 17. Fire hose with dust cap and dust plug. .......................................................................19

Figure 18. Polyurethane containment dike. .................................................................................19

Figure 19. Red paint crayons....................................................................................................20

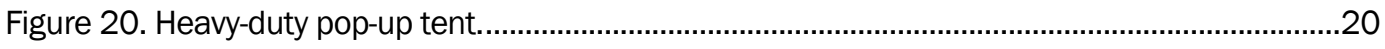

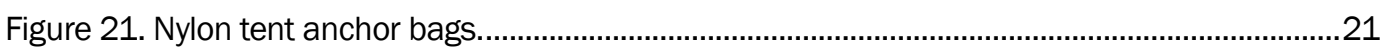

Figure 22. Water trash pump, discharge hose, suction hose, and strainer......................................22

Figure 23. Backpack leaf blower with extendable arm accessories..................................................22

Figure 24. Wet/dry Shop-Vac vacuum and accessories.................................................................2

Figure 25. Vinyl tarps. ...............................................................................................................2

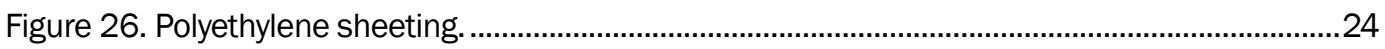

Figure 27. 30-ft-long electric water pipe heat cable. …………………………………………......2

Figure 28. In-line water heater..................................................................................................2

Figure 29. Unloading in-line water heater using metal ramp.......................................................26

Figure 30. Warning and danger signs adhered to container doors. .................................................26

\section{Tables}

Table 1. Inclement Weather Crater Repair Tool Kit contents. 


\section{Preface}

The Inclement Weather Crater Repair Tool Kit was developed for the U.S. Air Force Civil Engineer Center (AFCEC). The technical monitor was Dr. Craig Rutland, AFCEC.

The work was performed by the Airfields and Pavements Branch (GMA) of the Engineering Systems and Materials Division (GM), U.S. Army Engineer Research and Development Center, Geotechnical and Structures Laboratory (ERDC-GSL) and Fairlead Precision Integration and Manufacturing in Portsmouth, VA. At the time of publication, Dr. Timothy W. Rushing was Chief, CEERD-GMA; Dr. G. William McMahon was Chief, CEERD-GM; and Mr. R. Nicholas Boone, CEERD-GVT, was the Technical Director for Force Projection and Maneuver Support. The Acting Deputy Director of ERDC-GSL was Mr. Charles W. Ertle, and the Director was Mr. Bartley P. Durst.

COL Bryan S. Green was the Commander of ERDC, and Dr. David W. Pittman was the Director. 


\section{Unit Conversion Factors}

\begin{tabular}{|l|c|l|}
\hline Multiply & \multicolumn{1}{|l|}{ By } & To Obtain \\
\hline degrees Fahrenheit & $(\mathrm{F}-32) / 1.8$ & degrees Celsius \\
\hline feet & 0.3048 & meters \\
\hline gallons (US liquid) & $3.785412 \mathrm{E}-03$ & cubic meters \\
\hline inches & 0.0254 & meters \\
\hline pounds (force) & 4.448222 & newtons \\
\hline pounds (force) per square inch & 6.894757 & kilopascals \\
\hline
\end{tabular}




\section{Introduction}

\subsection{Background}

The U.S. Air Force's Rapid Airfield Damage Repair (RADR) Program developed technologies to return bomb-damaged runways and taxiways to full operational sortie production within 3 (objective) to $6.5 \mathrm{hr}$ (threshold) after an attack. The objective is the desired goal, and the threshold is the maximum time allotted for crater repair. Damaged pavements must be repaired using fast methods and durable materials to reduce the total time that the pavement is removed from service, as well as to reduce the need to conduct subsequent repairs to maintain an operable pavement surface, particularly during wartime scenarios. In addition to military wartime repair scenarios, damaged military and civilian airfields must also be repaired quickly; and these repairs must be capable of withstanding aircraft traffic at full operational levels to ensure long-lasting repairs.

Several airfield pavement repair kits, developed for various purposes, have been procured and deployed in recent years to provide all the supplies and equipment needed to perform pavement repairs in austere environments. The tool kits include the Sustainment Pavement Repair (SuPR) Kit, the Spall Repair Kit, the Expedient Crater Repair Kit, the Airfield Damage Repair (ADR) Tool Trailer, and Rubber Removal equipment. The equipment, methods, and materials for each scenario are standardized and can be used by all military services.

The technologies involved in the crater repair process of airfield pavements include compact track loaders (CTLs) with wheel saw, broom, and bucket attachments; wheeled excavators; front-end loaders; utility vehicles; extendable boom forklifts; simplified volumetric mixers; dump trucks; water trucks; flatbed trailers; rapid-setting cementitious materials; and a variety of concrete finishing tools.

These technologies and processes have been tested in cold, hot and dry, and wet weather. The ADR base recovery process may encounter situations in which crater repairs need to be conducted during periods of inclement weather (e.g., rainy or cold weather). These situations require additional materials and equipment to successfully complete the repairs. Various materials, equipment, and processes were evaluated in inclement 
weather conditions (Bell et al. 2013 and Edwards et al. 2013). Specific materials and equipment have been down-selected since the evaluations. An ADR tool trailer containing the necessary small tools and equipment for the ADR base recovery process was developed. However, a prepackaged supplemental tool kit was needed to ensure that the materials and equipment specific to inclement weather are readily available to the warfighters when necessary. The supplemental kit is the Inclement Weather Crater Repair Tool Kit described in this report.

\subsection{Objective and scope}

The objective of this project was to develop and procure a specialized prototype tool kit that included the materials and equipment necessary to supplement the basic crater repair package for use in inclement weather. The key parts of this research were to develop, procure, and evaluate special tools kits for augmenting the current ADR base recovery repair package. This involved (1) reviewing, evaluating, and specifying the necessary supplemental equipment and materials and (2) fabricating the prototype tool kit.

Chapter 2 summarizes crater repair research tests, Chapter 3 presents the contents of the prototype Inclement Weather Crater Repair Tool Kit, and Chapter 4 notes the conclusions. The items described in this report were included in the prototype kit. The fielded tool kits may have some approved item substitutions that were deemed equivalent to the prototype kit contents. 


\section{Inclement Weather Crater Repair Research}

This chapter gives an overview of the bomb-crater repair process and presents a summary of crater repair research conducted in wet weather (Bell et al. 2013, Pullen et al. 2014) and cold weather (Edwards et al. 2013) scenarios. The wet weather repairs were conducted in sustained rainfall of approximately 3/8-in. per hr, and the cold weather repairs were conducted in air temperatures between 33 to $35^{\circ} \mathrm{F}$.

\subsection{Crater repair process}

The crater repair process consists of eight key tasks conducted by teams of airmen using specific equipment and materials: (1) initial debris removal, (2) marking, (3) hauling, (4) saw cutting, (5) excavating, (6) backfilling, (7) capping, and (8) final debris removal. Figure 1 shows a 9-ft by 9-ft rapidsetting concrete crater repair before cure. The number of teams needed for repairing craters is dependent on the number of necessary repairs. Each task is completed using a set number of team members with the necessary equipment and materials. Each crater repair team is led by a Crater team leader who is responsible for accomplishing the repair objective, directing the repair personnel, and ensuring the quality of each repair.

Figure 1. Rapid-setting concrete crater repair.

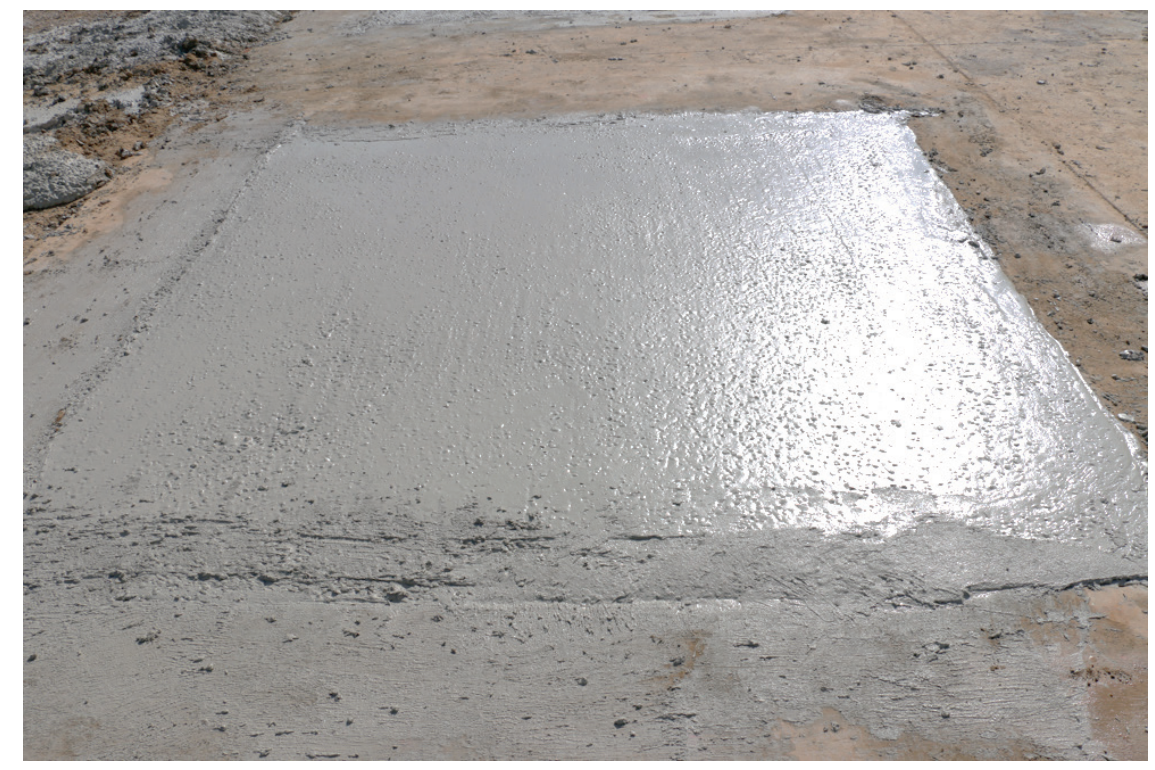


The first task for repairing craters is debris removal. The debris removal team begins the crater repair process by clearing the path from the staging area to the minimum operating strip (MOS) and then removing debris from each crater to be repaired in sequence.

The second task for crater repairs is hauling material. The haul team is responsible for mobilizing the repair materials and supplementary equipment from the staging area to the repair site. The primary repair materials requiring dedicated haul team assets include the super sacks of flowable fill and rapid-setting concrete, which are hauled from the storage site to the repair site (Figure 2). The repair materials and supplementary equipment are loaded onto a tractor-trailer.

Figure 2. Trailer hauling super sacks of cementitious material.

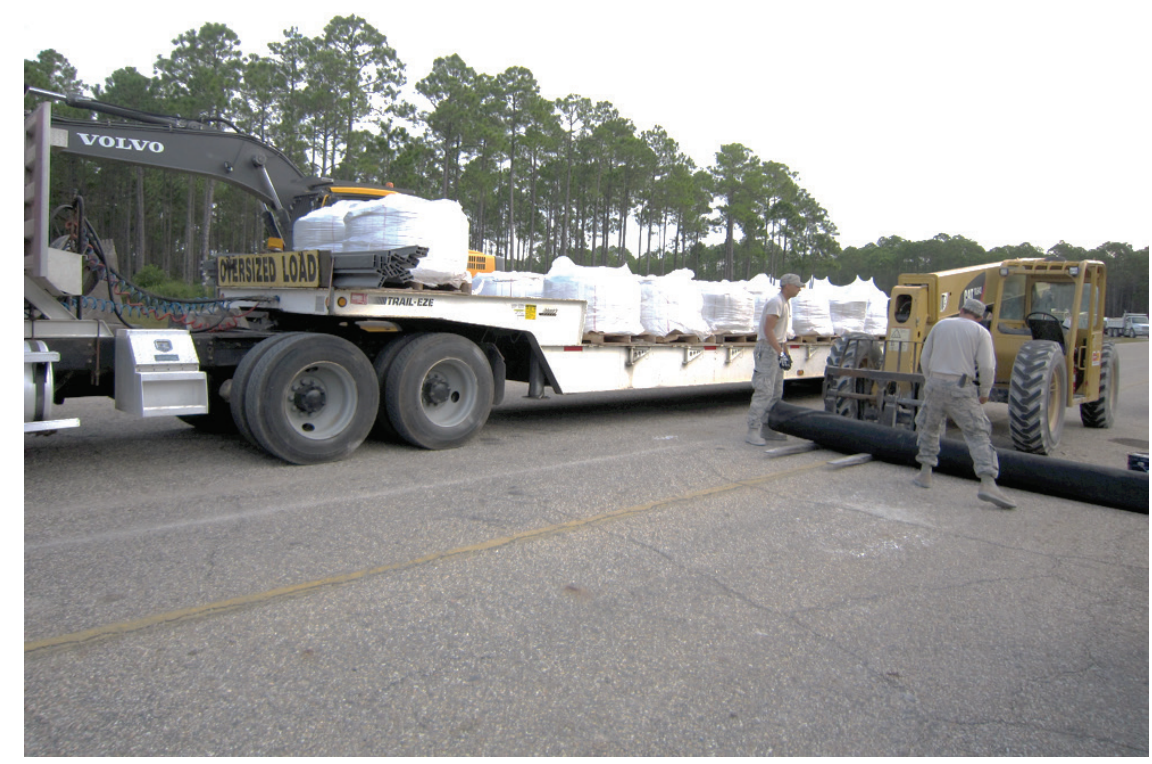

The marking team uses line-of-sight stanchions to help identify the crater upheaval. Stanchions consist of two sighting stands placed outside of the upheaved area and a target rod that is systematically moved within the upheaved area to determine where the upheaved pavement begins and ends. Figure 3 shows the stanchions being used during a wet weather crater repair test. Once the upheaval is identified, the marking team paints lines outlining the crater repair area as a guide for the saw-cutting team. 
Figure 3. Crater profile measuring using stanchions.

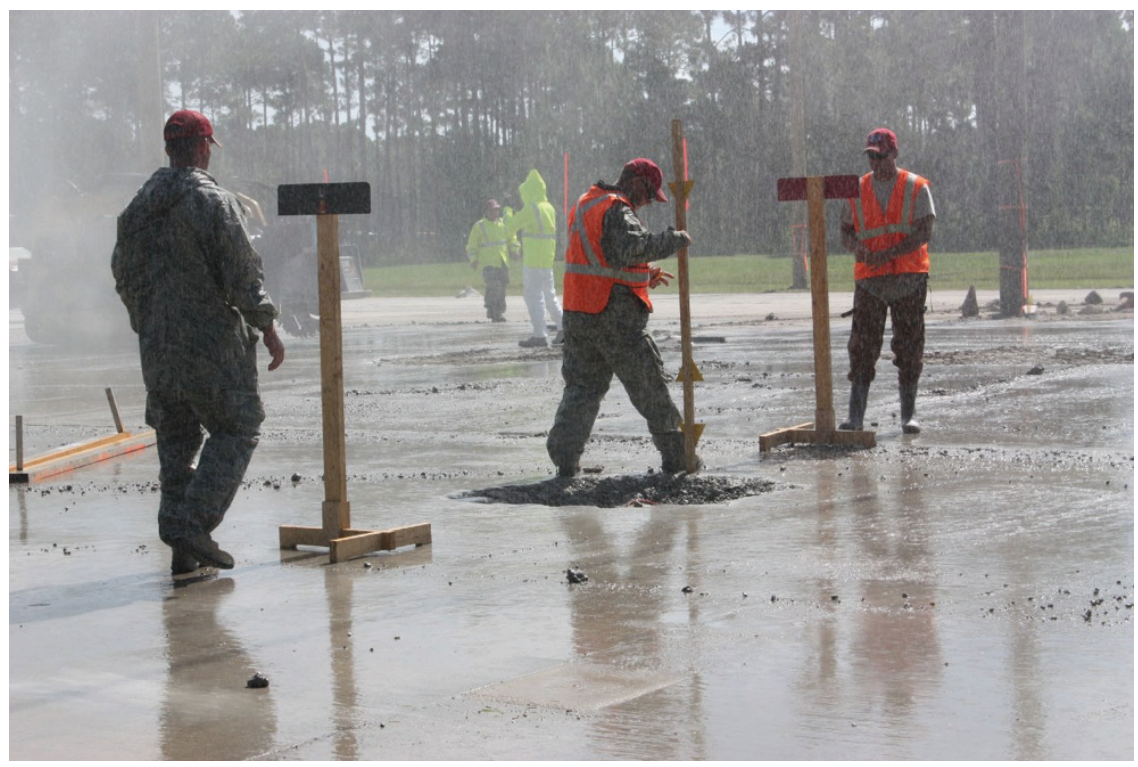

Saw cutting begins once the marking team completes its duties. Saw cutting can be the slowest task in the crater repair process. The current saw-cutting protocol calls for two wheel saws attached to CTLs to cut the crater upheaval simultaneously, as shown in Figure 4. Each wheel saw cuts two lines per crater. A walk-behind saw can be used in locations where dowel bars are present.

Figure 4. Saw cutting around crater upheaval.

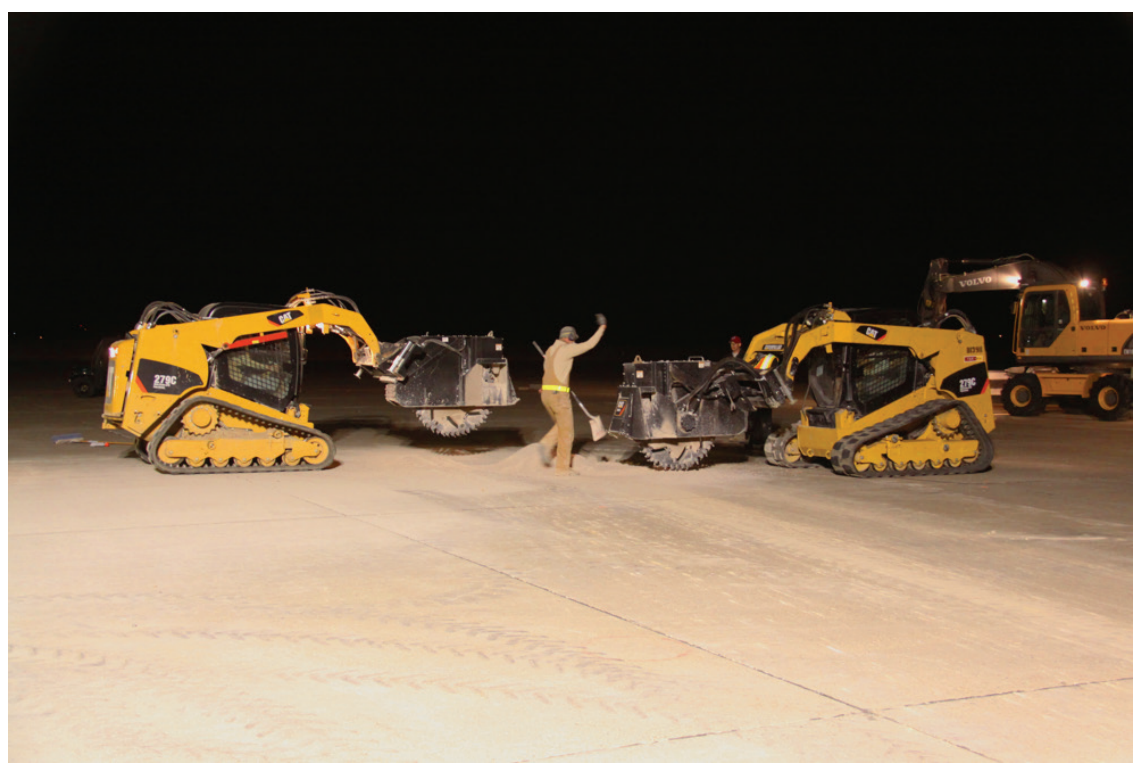


The excavation team is responsible for breaking up the damaged portland cement concrete (PCC) within the cut crater repair area and removing the disturbed subsurface material. An excavator with a hammer attachment is used for breaking any large sections of the existing pavement within the repair area, and a second excavator with a bucket attachment is used for removing the broken pavement and disturbed underlying material.

The backfill team, which utilizes the same personnel as the marking team, is responsible for filling the prepared excavation to the target surfacing depth, using material with sufficient bearing capacity to support heavy aircraft operations. Pre-blended rapid-setting flowable fill is the recommended material for backfilling craters. This material can be placed by using either dry or wet methods.

The dry method consists of emptying super sacks of the flowable fill material into the excavated crater, spreading the material, and then adding a predetermined amount of water on top of the dry material, completing the procedure in 4- to 6-in.-thick lifts. The dry method is conducted more commonly than the wet method due to its simplicity and minimal equipment requirements. Figure 5 shows a super sack of flowable fill being dumped inside the repair.

Figure 5. Placing flowable fill backfill using the dry method.

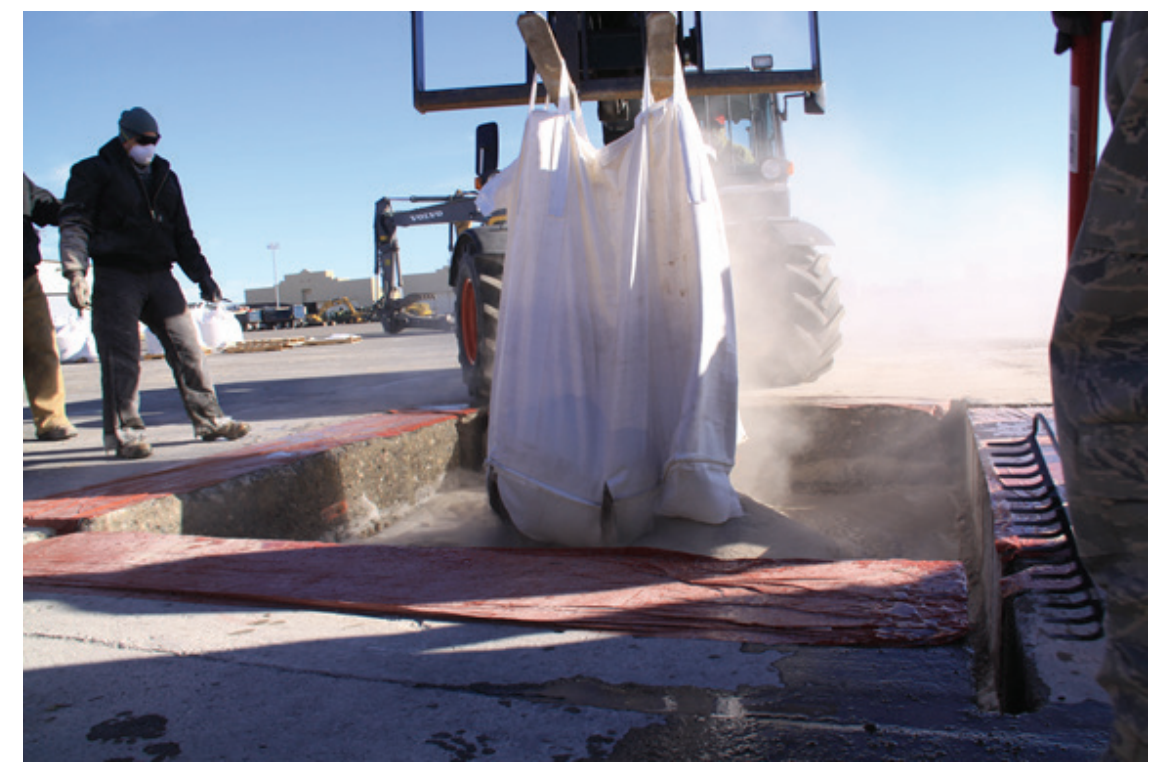

The wet method is completed by using a simplified volumetric mixer. Procedures for mixing and placing rapid-setting flowable fill using the volumetric mixer include filling the dry material bin with the pre-blended 
rapid-setting flowable fill, filling the water tanks of the mixer, applying a release agent to the mixer chute and hand tools, adjusting the machine to the flowable fill setting to ensure the appropriate quantity of mix water, and placing the mixed backfill into the excavated crater as needed. Wetplaced rapid-setting flowable fill is extremely fluid and self-leveling while still able to set within 30 min of placement to allow for placement of the crater cap material. Figure 6 shows the simplified volumetric mixer.

Figure 6. Simplified volumetric mixer.

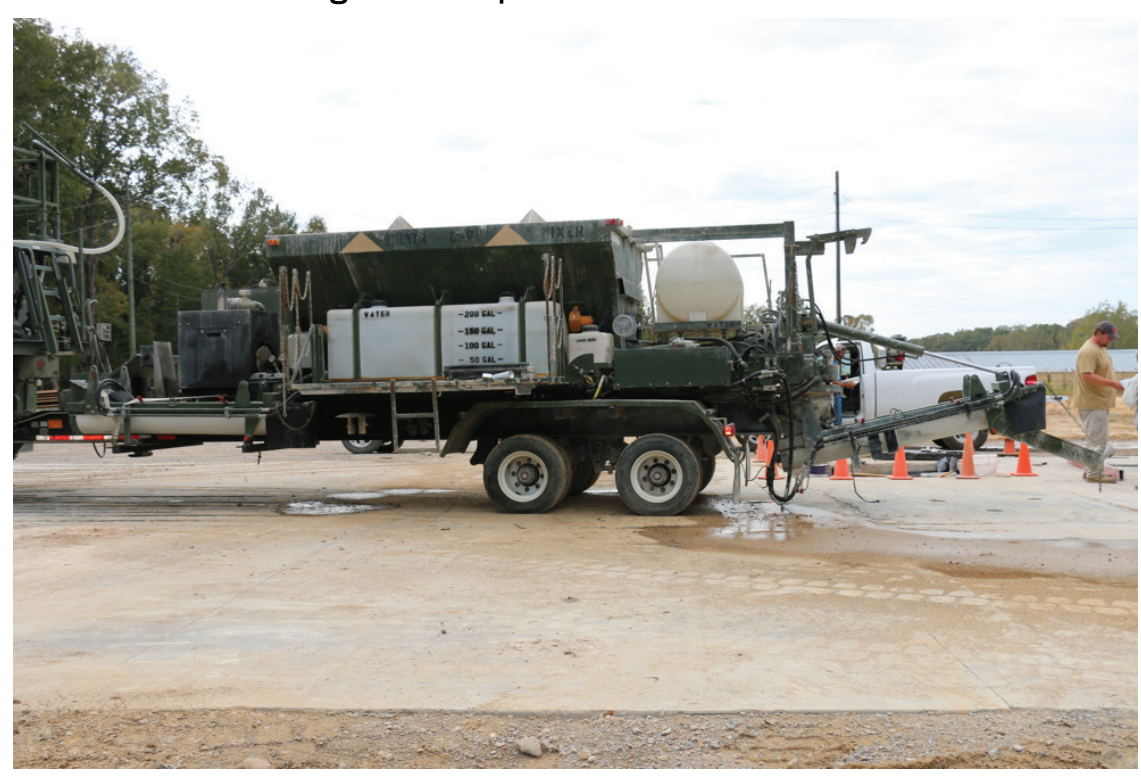

Concrete capping is the seventh task in the crater repair sequence. The capping team is responsible for placing a level pavement surfacing capable of supporting heavy aircraft operations within the objective time threshold. Rapid Set Concrete Mix ${ }^{\circledR}$ or hot-mixed asphalt (HMA) can be used as capping material for crater repairs. The mixing and placement of the capping material is conducted using only the simplified volumetric mixer (Figure 6) for PCC or appropriate HMA batching and placement equipment. Figure 7 shows a repair being capped with Rapid Set Concrete Mix $^{\circledR}$ using the simplified volumetric mixer.

The final task in the crater repair sequence consists of final debris clearance. Angle brooms, foreign object debris (FOD) removal equipment, and vacuum trucks are used to remove any debris remaining from the original damage or the repair process. The PCC or HMA crater caps are allowed to cure or cool, respectively, while the final debris removal is conducted. 
Figure 7. Crater repair with Rapid Set Concrete Mix ${ }^{\circledR}$ using the volumetric mixer.

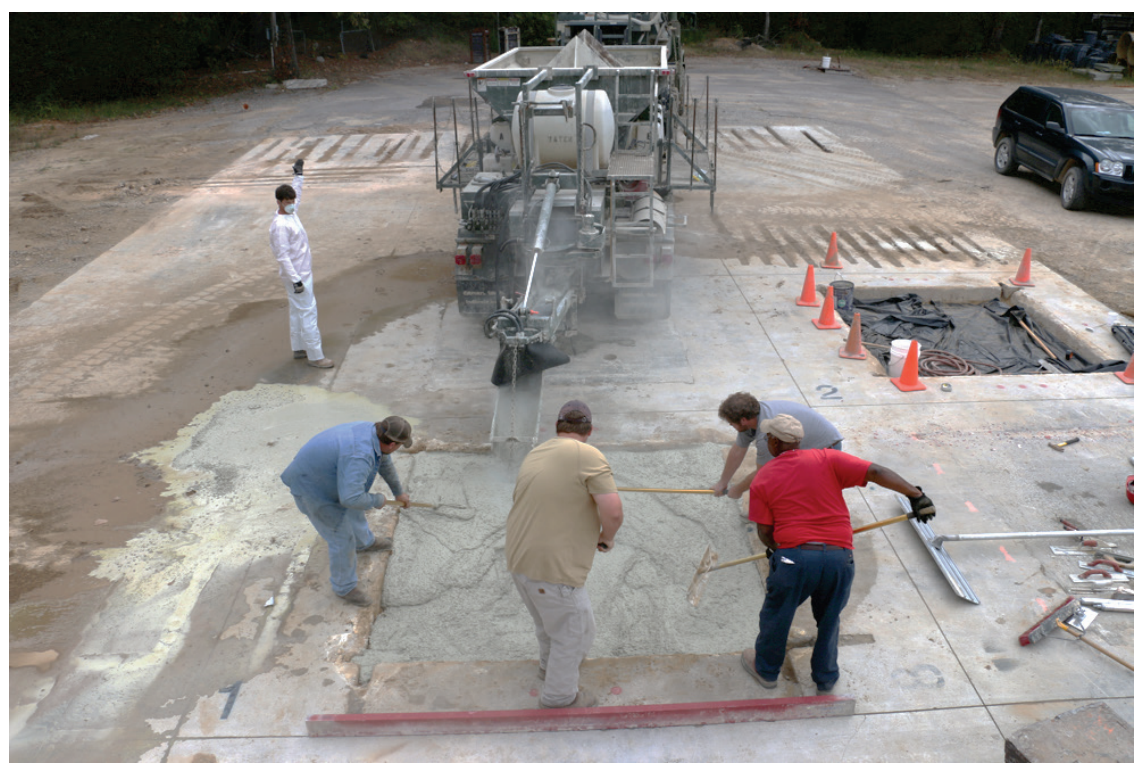

The results of many full-scale tests of the crater repair process previously described led to the development of an ADR equipment set and an ADR tool trailer kit to be deployed to various military airfields. The specific equipment, tools, and materials are needed to complete the key crater repair tasks. The generic ADR equipment set for crater repairs consists of

- Graders,

- Dozer,

- Loaders,

- Tractors,

- Trailer (6o-ton lowboy),

- Vacuum sweepers,

- Tractor-mounted sweepers,

- Warehouse forklift (6,0oo lb),

- Trailer (40 ft) - material,

- Extendable boom forklifts (11,00o lb),

- Extendable boom forklift attachment package,

- Dump trucks,

- Wheeled excavators,

- Excavator attachment package,

- Pneumatic rollers,

- Vibratory rollers,

- Water truck (1,500 gal),

- Compact track loader (CTL), 
- CTL attachment package,

- Trailer (40 ft) - attachments,

- Volumetric mixer,

- Water trailer (2,00o gal),

- Asphalt recycler,

- Light carts, and

- Dump truck water skids (1,00o gal).

The ADR Tool Trailer consists of over 150 items -- including tools, materials, and small equipment -- needed to perform small and large crater repairs. The Inclement Weather Crater Repair Kit was developed as a supplemental kit to the ADR Tool Trailer to provide additional tools and materials necessary for the repair of craters under wet weather or cold climate conditions.

\subsection{Cold weather crater repair testing}

Full-scale timed tests on concrete crater repairs conducted in cold weather were performed at Malmstrom Air Force Base in Great Falls, MT, in March 2012 (Edwards et al. 2013). The main objective of this cold weather crater repair test was to learn how sustained cold temperatures of less than $40^{\circ} \mathrm{F}$ affect equipment operation and repair material performance. Air temperatures during the test were between 33 and $35^{\circ} \mathrm{F}$. The wind chill temperatures were between 23 and $27^{\circ} \mathrm{F}$.

The crater repair tasks were conducted in the cold weather in the same manner as if they were being repaired in hot, dry weather. However, because of the cold air temperatures, an additive was used for the capping material. Aluminum sulfate was added to the mix water before the placement of the Rapid Set Concrete Mix ${ }^{\circledR}$. Aluminum sulfate is an additive intended to reduce the amount of curing time so that the surface will set. Rapid Set Concrete Mix ${ }^{\circledR}$ has a normal set time of 20 to 30 min, depending on the air temperature. However, the set time was anticipated to increase at temperatures below $40^{\circ} \mathrm{F}$.

Additional technologies, such as curing blankets and plastic sheeting, were evaluated. The curing blankets were used in the cold weather to help trap some of the exothermic heat while the concrete cured. The plastic sheeting served the same purpose. However, it was determined that the curing blankets and plastic sheeting were not necessary for the concrete curing. 
In some instances, it appeared that covering the repairs made the curing process excessively slow.

The debris removal, damage delineation, marking process, upheaval and disturbed material removal, and backfilling processes (dry method) were not affected by the cold weather; all the equipment for the repairs worked well in the low temperatures. However, there was an increased potential for shrinkage cracks in the rapid-setting concrete cap when the air temperature was below $40^{\circ} \mathrm{F}$. The shrinkage cracks that formed because of the low temperature did not seem to affect performance. There was concern that the manufacturer had not included the shrinkage-reducing admixture due to an error at the plant.

Two hours after the completed repair of the final crater, each repair was trafficked to 112 passes of simulated F-15E aircraft loads. The 112-pass level is the threshold established for expedient RADR repairs. The singlewheel F-15E load cart was rigged such that the aircraft tire was loaded to approximately 35,235 lb with 325-psi tire pressure, representative of the maximum loading for the $\mathrm{F}-15 \mathrm{E}$ aircraft. Core samples of the rapid-setting concrete caps extracted from the five repairs resulted in an average 28-day compressive strength of $5,800 \mathrm{psi}$, which was over the requirement of 5,000 psi.

\subsection{Wet weather crater repair testing}

Wet weather crater repair testing was completed for concrete repairs at the Silver Flag Exercise Site in Tyndall Air Force Base, FL, in June 2012 (Bell et al. 2013). Wet weather crater repair testing was completed for asphalt repairs at the same test site in September 2013 (Pullen et al. 2014). The main objective of the wet weather crater repair tests was to evaluate the materials, equipment, and processes under inclement weather conditions of sustained rainfall. The air temperatures ranged from 77 to $89^{\circ} \mathrm{F}$ during the concrete tests and 71 to $84^{\circ} \mathrm{F}$ during the asphalt tests.

Simulated rainfall was made possible by the construction of a sprinkler system mounted on ten 40 -ft-high wooden utility poles (Figure 8 ). The utility poles supported cables with polyvinyl chloride (PVC) pipes mounted with sprinkler heads above the test area. The $75^{-}$by $200-\mathrm{ft}$ sprinkler system simulated constant rainfall of $3 / 8$ in. per hr during each test. 
Figure 8. Calibrated sprinkler system used for wet weather crater repair tests.

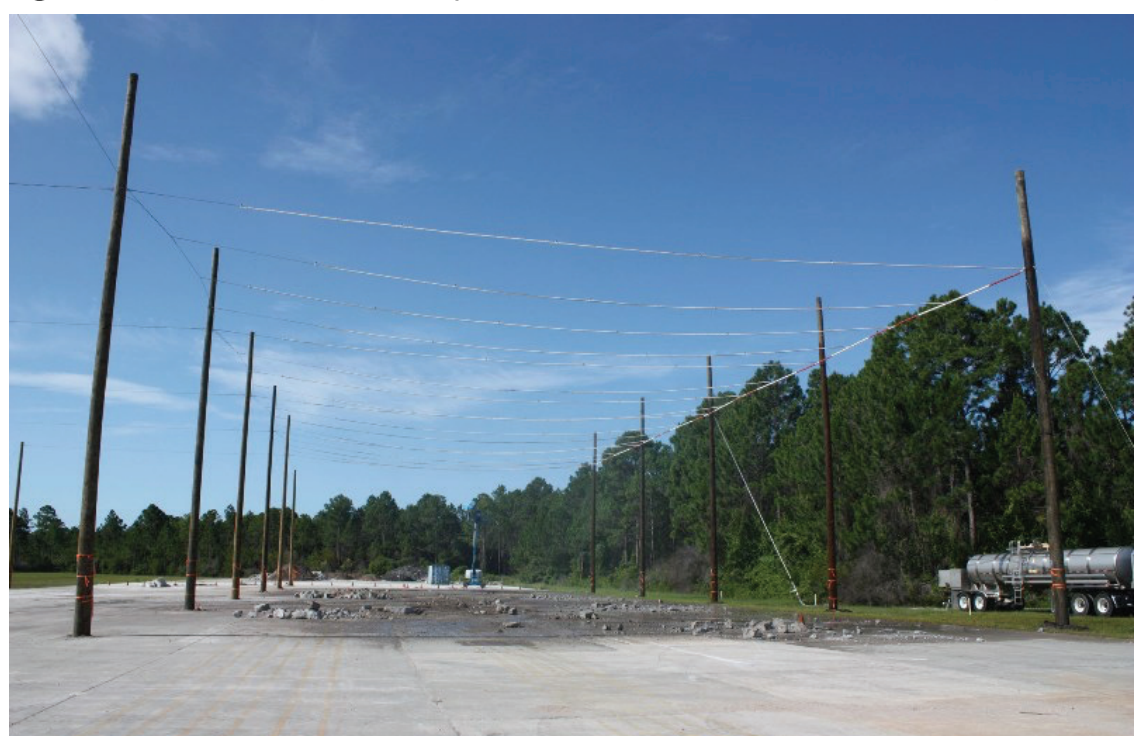

Additional equipment and supplies were required to mitigate the potential for adverse impact of the rainfall during the crater repair process. These items included solid paint crayons for marking pavement, pop-up tents for placing the rapid-setting concrete caps, crater caps for mitigating the entrance of water into the repairs during cure times, barriers for surface runoff, backpack leaf blowers, and tarps for mitigating water into the repairs during HMA cap placement. These items are necessary to ensure quality repairs during wet conditions.

For the concrete crater repair tests, initial debris removal, marking and damage delineation, and backfilling processes were not affected by the wet weather. All equipment performed well. The rapid-setting flowable fill (dry method) and the rapid-setting concrete material met the strength requirements for concrete crater repair despite the wet weather. The typical strength observed for the rapid-setting flowable fill placed by using the dry method under the wet weather conditions was $100 \mathrm{CBR}$ with two out of the six craters showing lesser strength profiles ranging from 40 to $80 \mathrm{CBR}$. The rapid-setting concrete cap produced average compressive strengths of 6,700 psi, well in excess of the typical 5,000 psi required for airfield pavements.

All rapid-setting concrete repairs were able to sustain the threshold traffic for expedient repairs of 112 passes of the F-15E load cart. No cracking was observed after the initial 112 passes. The crater that showed the greatest potential for FOD after it was repaired sustained 3,500 passes (the 
sustainment level of traffic) of the F-15E load cart without any excessive cracking or increased FOD potential.

For the asphalt crater repair tests, the equipment was not significantly affected by the wet weather. Water mitigation and removal techniques adequately maintained dry areas of HMA capping operations. Dump truck and ground stockpile HMA storage methods both maintained a minimum HMA temperature of $280^{\circ} \mathrm{F}$ for $1.5 \mathrm{hr}$. Also, initial profile measurements indicated $100 \%$ of the HMA repairs met the repair quality criterion of being within \pm 0.75 in. of the existing pavement.

After completion of the six repairs, each asphalt-capped repair was subjected to 112 passes of fully loaded simulated F-15E traffic. Rut depth measurements after trafficking showed that the HMA repairs deformed less than $0.125 \mathrm{in}$. The repair that showed the greatest potential for failure was trafficked further. After 1,984 passes, traffic was stopped due to reaching 1 in. of permanent surface pavement deformation. Also, the repair presented a tire hazard because the HMA surface had debonded from the flowable fill surface, beginning around pass 500 . 


\section{Inclement Weather Crater Repair Tool Kit Contents}

The Inclement Weather Crater Repair Tool Kit prototype was developed following the conclusion of the wet weather and cold weather crater repair tests described in Chapter 2. The results and the lessons learned from the full-scale experiments aided in the selection of the necessary kit contents described in this chapter. The intention of the Inclement Weather Crater Repair Tool Kit is to supplement the ADR Tool Trailer.

The Inclement Weather Crater Repair Tool Kit includes approximately 20 different items plus their respective accessories strategically packed into two quadcon dry freight ISO cargo containers. The generic kit contents, including items from Container 1 and Container 2, are presented in Table 1. The contents include items and equipment needed for asphalt and concrete crater repairs in wet or cold weather. The packaged weights of Container 1 and Container 2 are approximately 3,210 and 5,890 lb, respectively.

The design drawings of the kit are provided in Appendix A. The drawings include detailed information about each container's outfitting and the kit contents, item locations, dimensions, and weights. The drawings also show various views of the containers. The quadcon containers and each individual tool, equipment, basket, bolt, etc. were assigned an item number, as shown in the tables of Appendix A. The item numbers shown in parentheses in the following paragraphs are referencing the item numbers shown in the table located on Sheet 2 in Appendix A.

The corrugated steel quadcons (Item 1) are equipped with double swing doors on both ends of the containers (Figure 9). Each quadcon is approximately $8 \mathrm{ft}$ long, $8 \mathrm{ft}$ high, and $4 \mathrm{ft} 9.5 \mathrm{in}$. wide and weighs approximately $2,500 \mathrm{lb}$ empty. The quadcon containers allow the kits to be deployable with their four-way fork-lift pockets and provide an option to be attached together using the connecting couplers (Figure 10). Four quadcon containers coupled together makes up one standard 20-ft ISO container. 
Table 1. Inclement Weather Crater Repair Tool Kit contents.

\begin{tabular}{|l|c|c|}
\hline Description & Quantity & Container \\
\hline dry-line marker & 1 & 1 \\
\hline 30-ft-long custom fire hose & 18 & 2 \\
\hline 2.5-in.-diameter dust cap coupler (for fire hose) & 18 & 2 \\
\hline 2.5-in-diameter dust plug adapter (for fire hose) & 18 & 2 \\
\hline 10-ft-long polyurethane containment dike & 36 & 2 \\
\hline 12-in.-diameter No. 10 sieve & 4 & 2 \\
\hline 20-ft x 100-ft plastic sheeting & 2 & 2 \\
\hline 16-ft x 20-ft 18-oz. vinyl-coated tarp & 24 & 2 \\
\hline 5-gal wet/dry vacuum, hose, and accessories & 1 & 1 \\
\hline backpack leaf blower with extensions & 3 & 1 \\
\hline 5-gallon plastic buckets with lids & 36 & 1 \\
\hline 10-ft x 10-ft heavy duty pop-up tent & 10 & 2 \\
\hline red or orange paint crayons, 12 count & 5 & 1 \\
\hline 30-ft-long pipe heater cable & 2 & 1 \\
\hline 18-ft-long automatic electric heat cable & 2 & 1 \\
\hline nylon tent anchor bags & 44 & 2 \\
\hline multi-fuel in-line water heater & 1 & 1 \\
\hline 3-in. centrifugal water pump - 290 gal/min & 1 & 1 \\
\hline metal suction hose strainer (for water pump) & 1 & 1 \\
\hline 20-ft-long suction hose (for water pump) & 1 & 1 \\
\hline 50-ft-long discharge hose (for water pump) & 1 & 1 \\
\hline aluminum scoop & & \\
\hline
\end{tabular}

Figure 9. Corrugated steel quadcons.

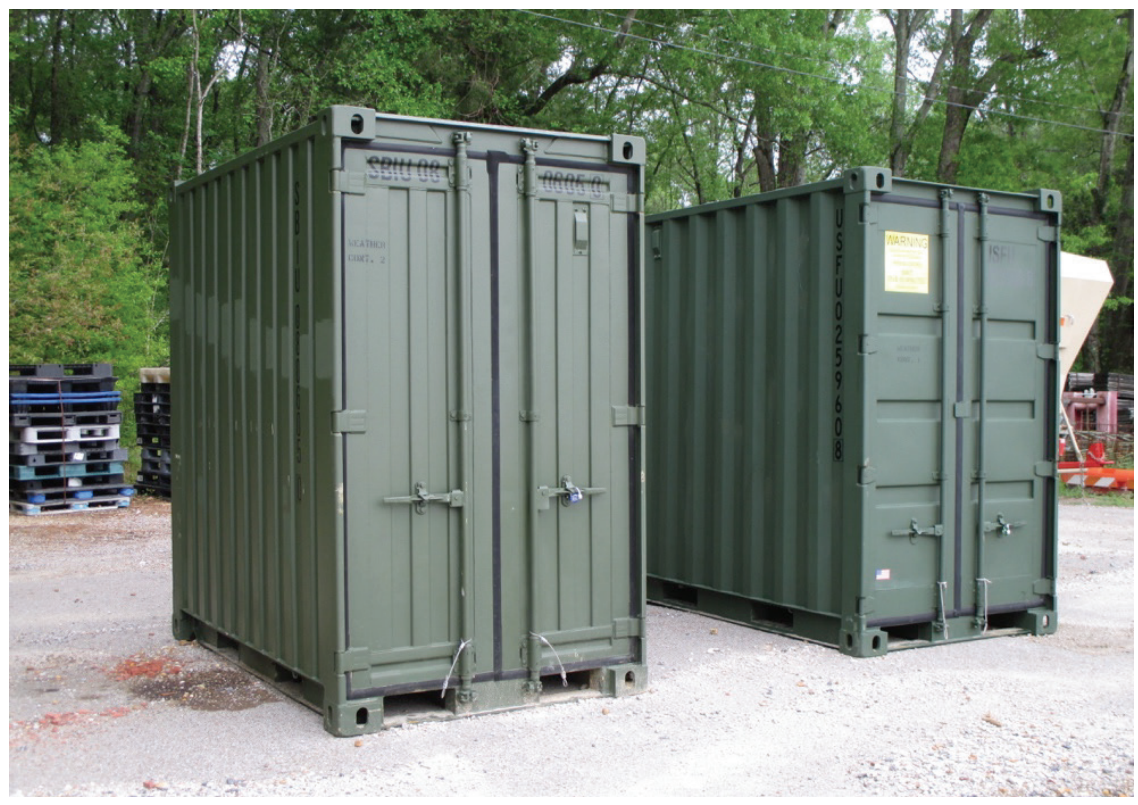


Figure 10. Quadcon connecting couplers.

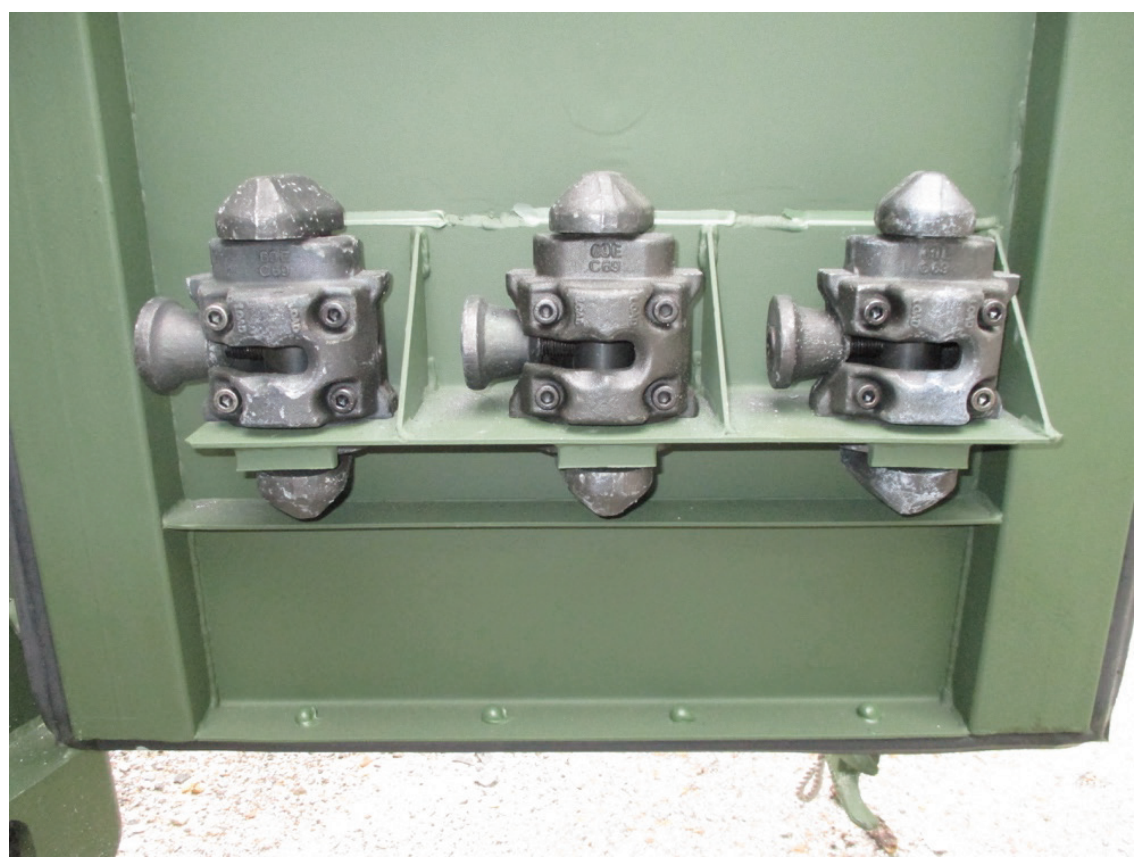

Inside the kit, wire baskets (Items 30 and 31) and a 50-gal plastic tote (Item 37) are used to hold smaller, loose items. Figure 11 shows one of the three wire baskets, and Figure 12 shows the plastic tote used to hold the smaller miscellaneous items in the prototype kit.

Figure 11. Collapsible wire basket.

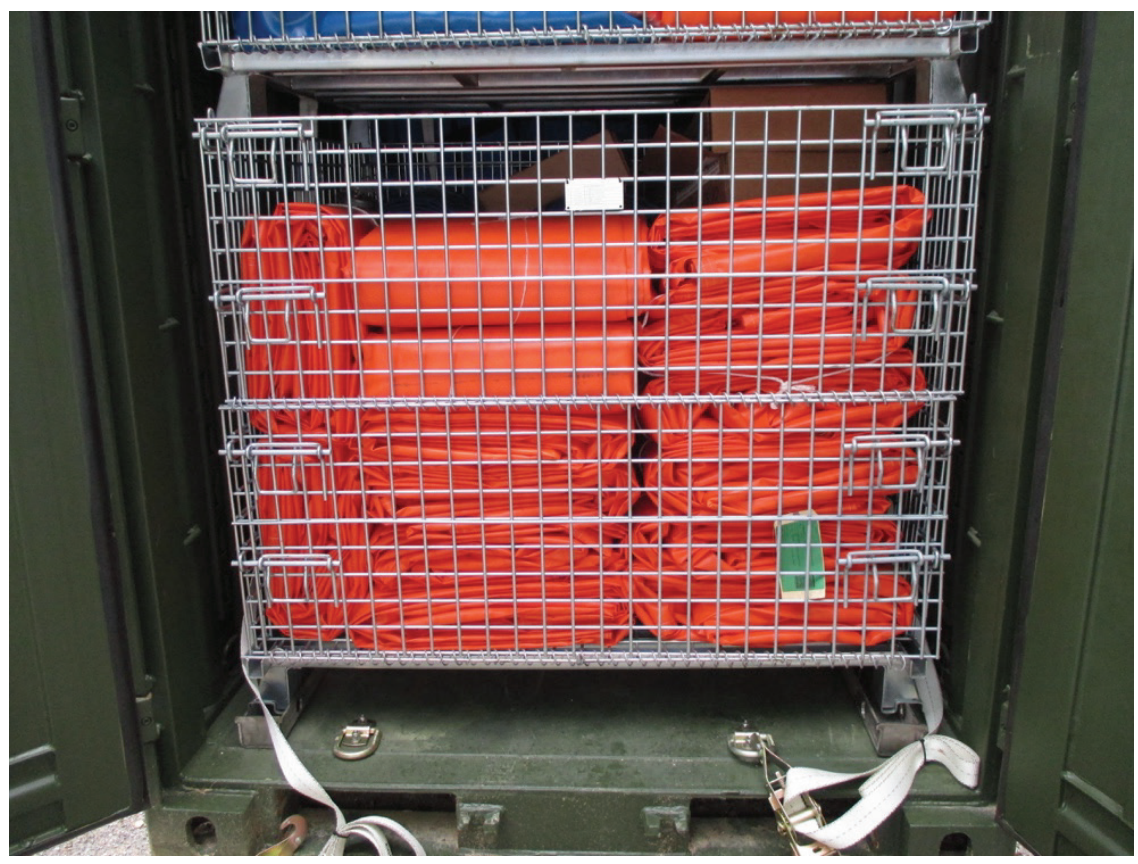


Figure 12. 50-gal plastic tote.

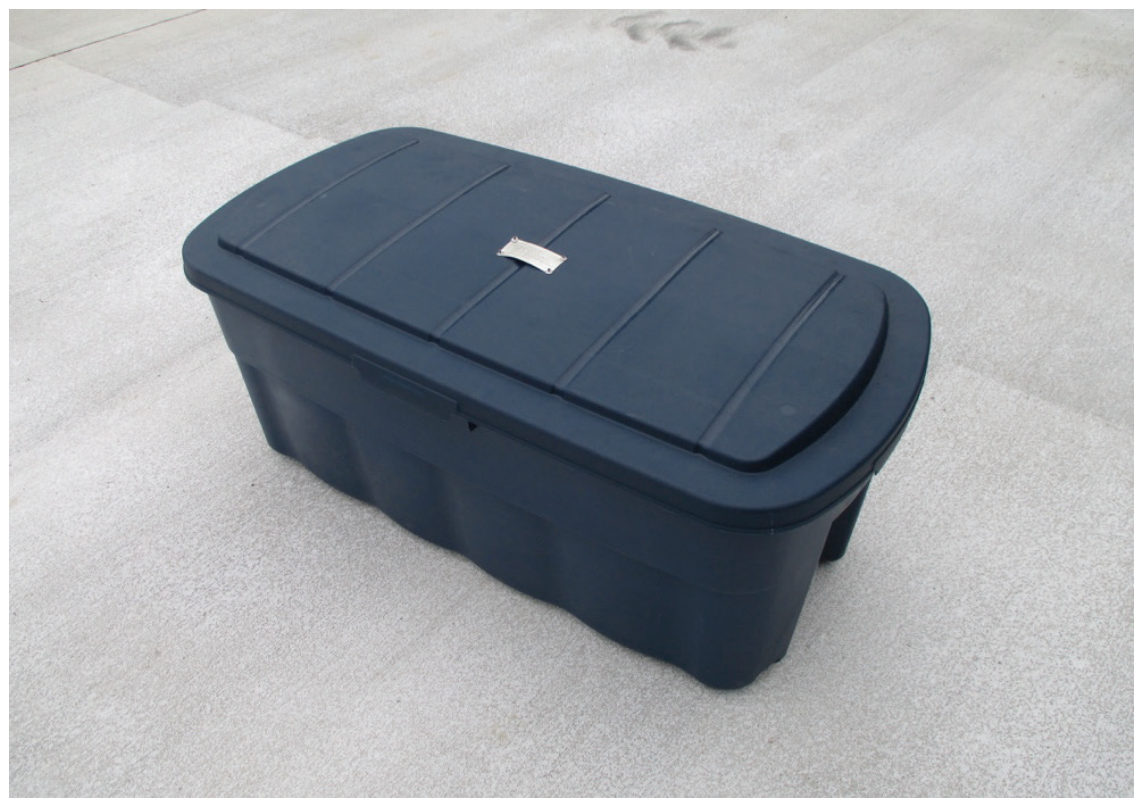

The larger, heavier items are placed on the container floor or mounted on the container walls and are secured using various-sized ratchet straps (Items 24 and 41). The larger tie-down cargo aircraft ratchet straps are about $1.75 \mathrm{in}$. wide and $20 \mathrm{ft}$ long with steel connectors and are made of nylon webbing. The smaller polyester ratchet straps are $1 \mathrm{in}$. wide by $2 \mathrm{ft}$ long and include coated S-hooks. Figure 13 shows the two ratchet-strap sizes used in the kit.

Figure 13. Ratchet straps.
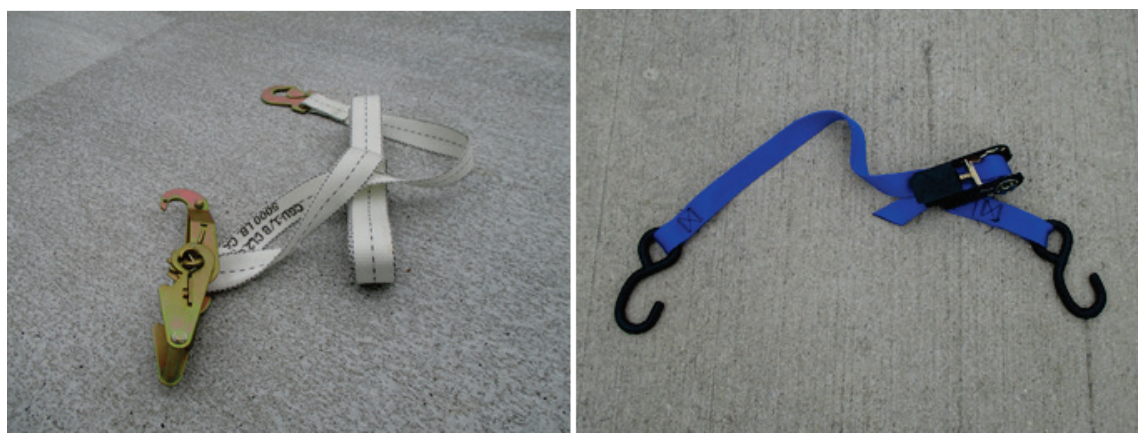

The 1.75-in.-wide by 20-ft-long ratchet straps were used to secure the items on the floor, in the wire baskets, and on the walls. The 1-in.-wide by 2-ft-long ratchet straps were used to secure the hoses of the backpack leaf blowers to the wall. The ratchet straps are secured to the floor or walls of the container using welded stud (Item 23), hexagonal nut (Item 25), washer (Item 26), and surface mount rope ring (Items 29 and 34) systems (12,000- or 1,00o-lb working limit), as shown in Figure 14. 
Figure 14. 12,000-lb (left) and 1,000-lb (right) surface mount rope rings.

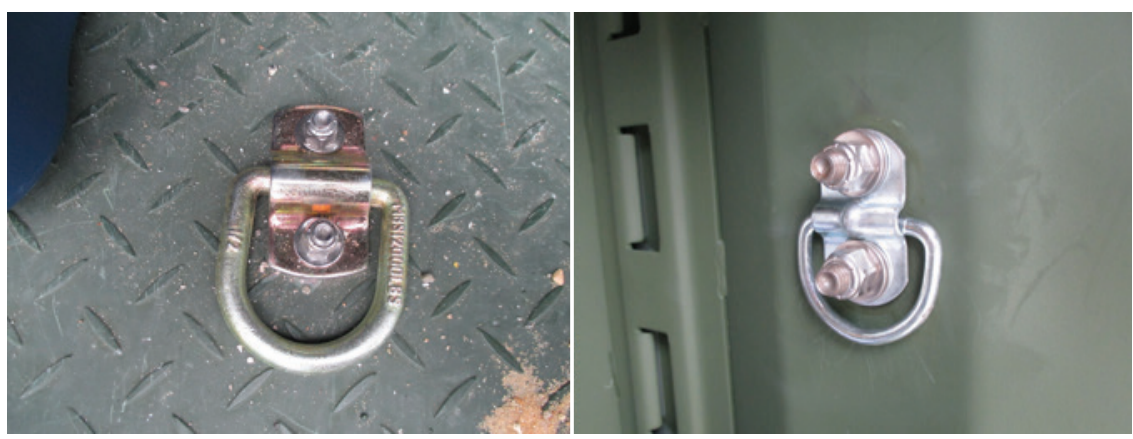

Metal placards were secured to the inside of the container doors, displaying the contents of each container. Metal placards were also installed on the outside of each wire basket and the plastic tote, identifying their respective contents. Figure 15 shows a label attached to one of the wire baskets.

Figure 15. Metal label attached to wire basket.

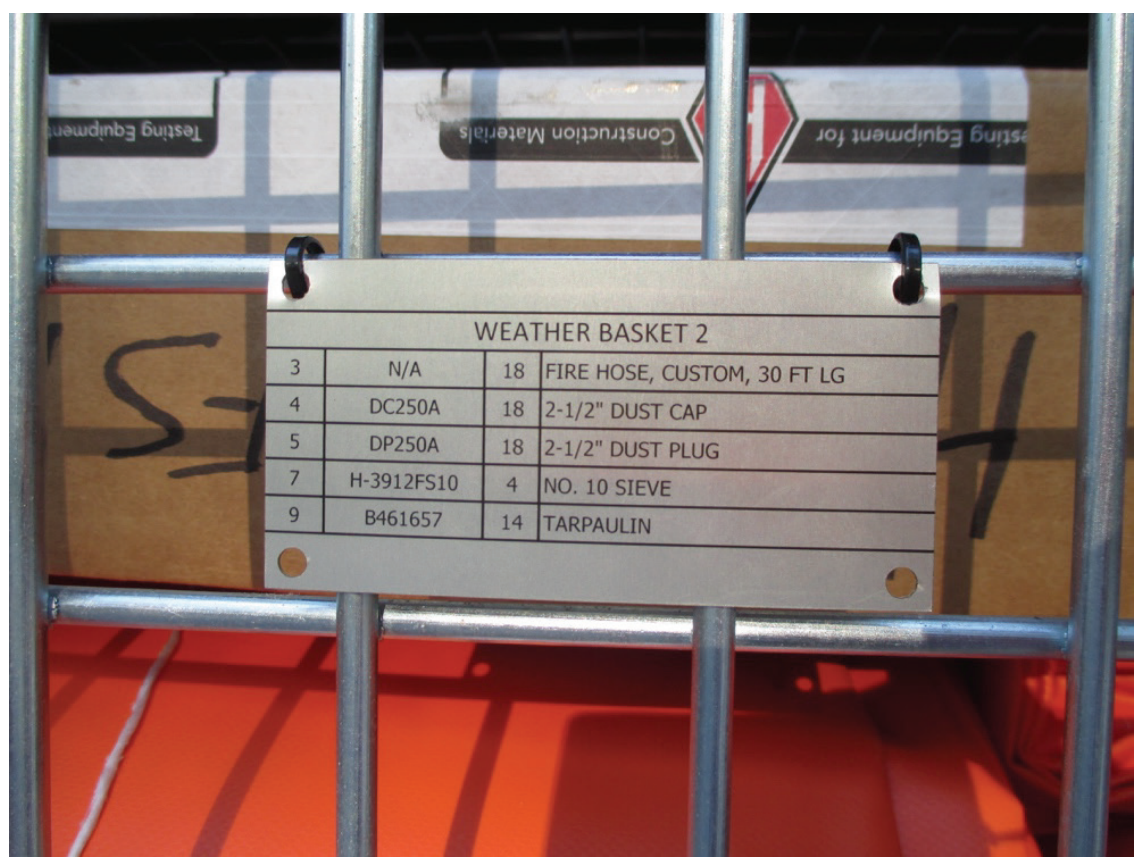

A few of the items in the kit are redundant, particularly the items acting as a water barrier surrounding the perimeter of the open repair to mitigate surface water runoff into the open repair. These redundancy items include the [1] dry-line marker (Item 2), which inherently includes the small shovel (Item 49), 5-gal buckets (Item 12) and bucket lids (Item 13), and the sieves (Item 7); [2] the fire hoses (Item 3), which inherently include the 2.5-in. dust caps (Item 4) and dust plugs (Item 5); and [3] the containment dikes (Item 6). Figure 16, Figure 17, and Figure 18 show each of these items, 
respectively. Only one of these technologies is needed to perform as a water barrier around the open repairs. Once users analyze the prototype kit, the barrier items will be down-selected.

Figure 16. Dry-line marker, No. 10 sieve, 5-gal bucket with lid, and scoop.

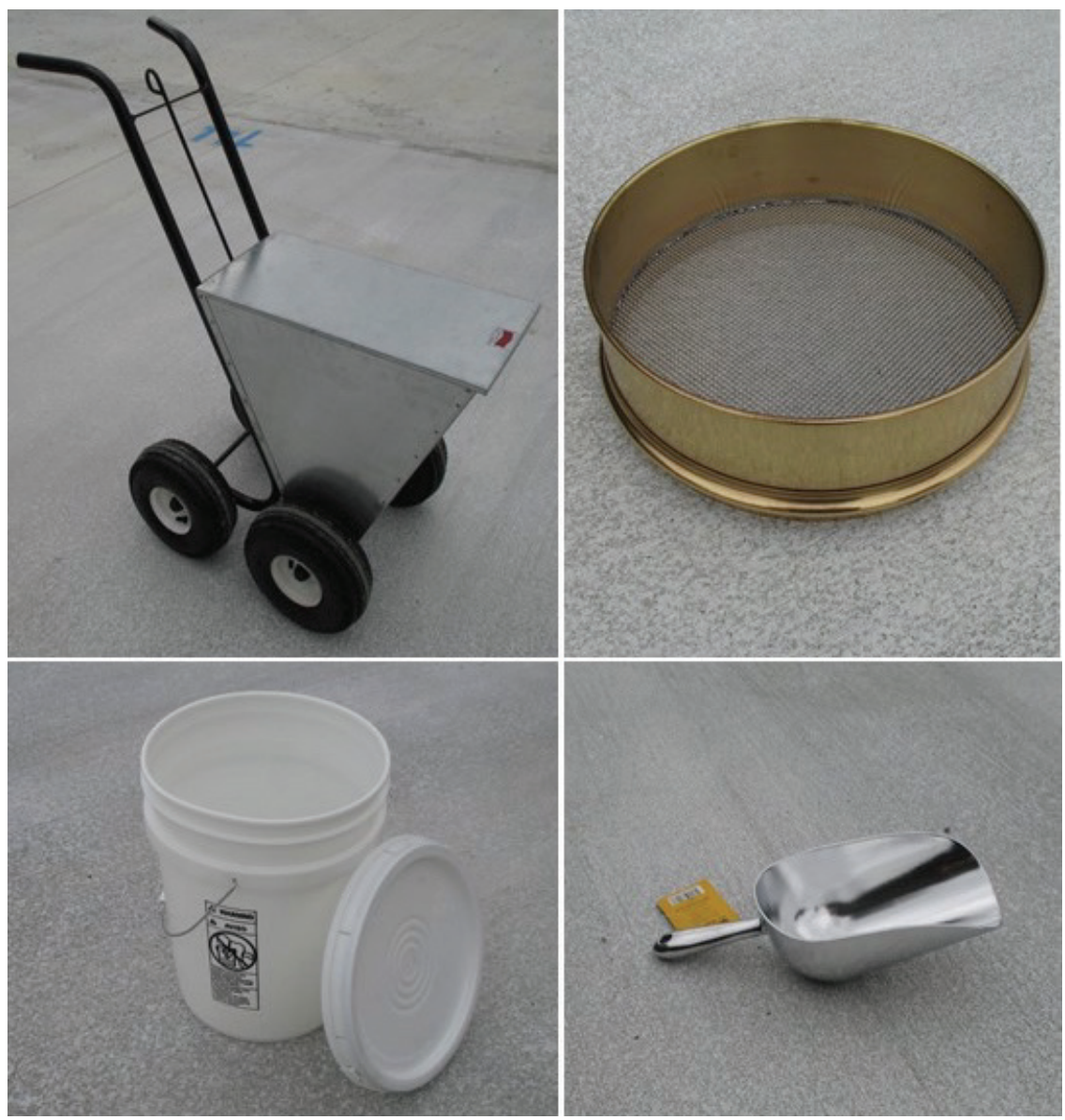

The empty 5-gal buckets and lids are for collecting sand in theater to use with the dry-line marker and for other needs, such as bailing water out of the crater repair areas or collecting the initial discharge from the volumetric mixer. The collected sand is sieved by hand directly into the buckets by using the No. 10 sieves. This eliminates large aggregates or trash from clogging the dry-line marker when it is used to form a waterproof barrier around the perimeter of the open crater repair area. The small hand shovel/scoop is used to scoop the sand out of the buckets and into the dry-line marker. 
Figure 17. Fire hose with dust cap and dust plug.

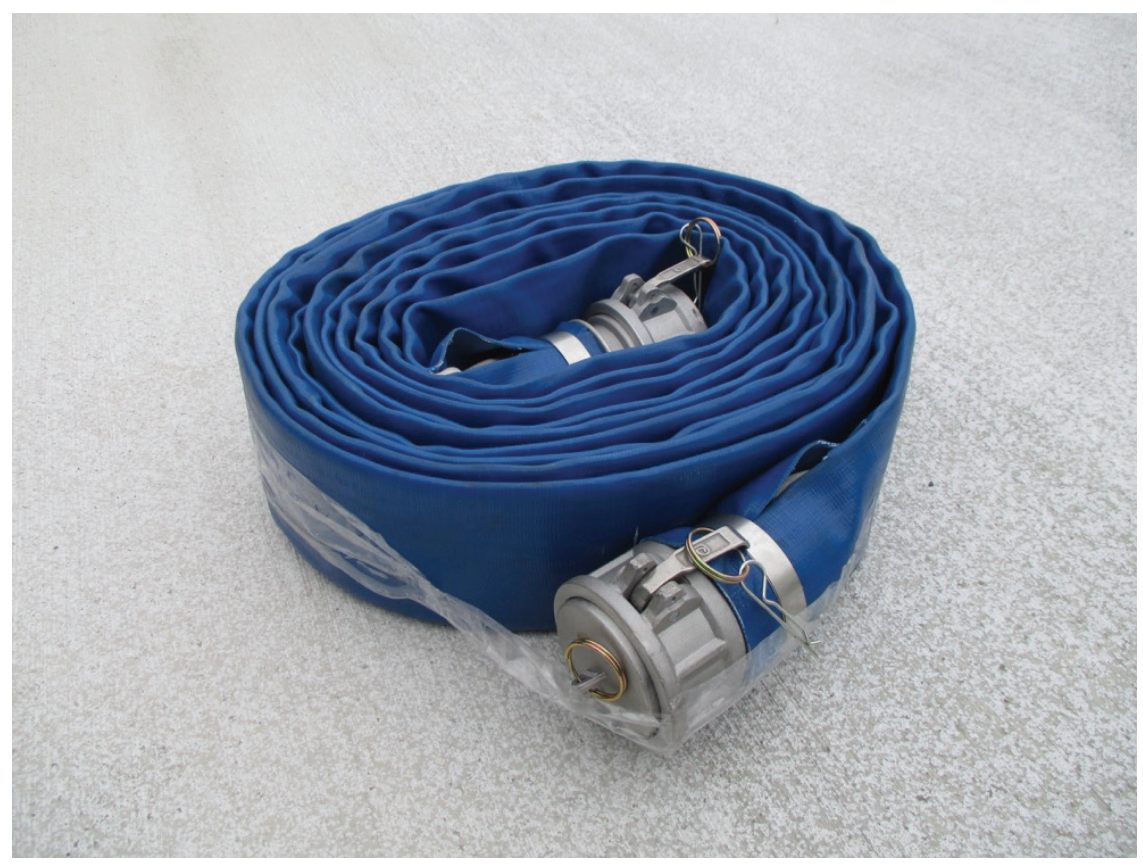

Figure 18. Polyurethane containment dike.

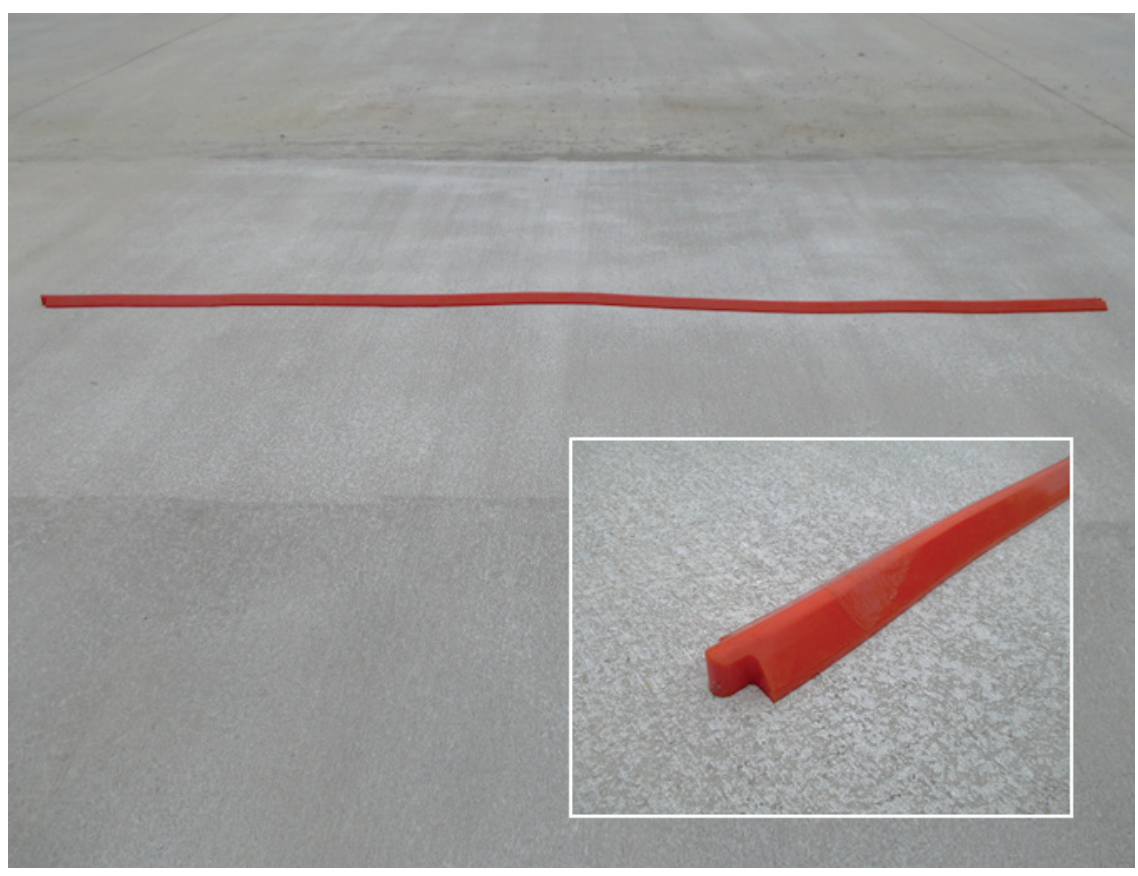

The paint crayons (Item 15) are used for marking the area for the saws to cut around the upheaval. Paint crayons (Figure 19) are used in place of marking spray paint during rainy weather because the paint crayons are waterproof. Red paint crayons are specified for the kit; however, orange paint crayons are another color option, as they are just as visible during rainy weather. 
Figure 19. Red paint crayons.

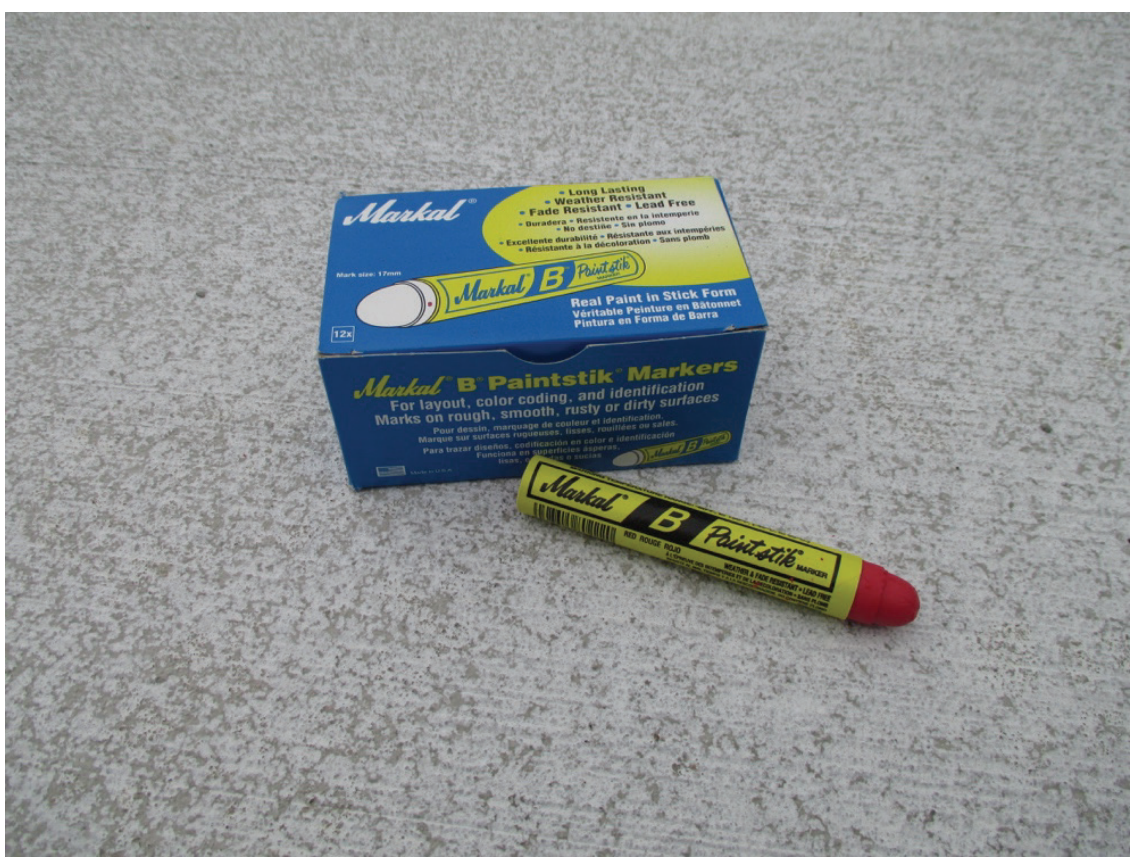

The 10-ft by 10-ft pop-up tents (Item 14) are made of a heavy-duty industrial-grade 6061-T6 anodized aluminum frame with a vinyl cover. The tents are used to protect the open repair area and the discharge chute of the volumetric mixer during the placement of the rapid-setting concrete caps. The tent anchor bags (Item 18), when filled with sand or aggregate, are used to weigh down the tents during windy conditions. Figure 20 shows the pop-up tent, and Figure 21 shows the tent anchor bags.

Figure 20. Heavy-duty pop-up tent.

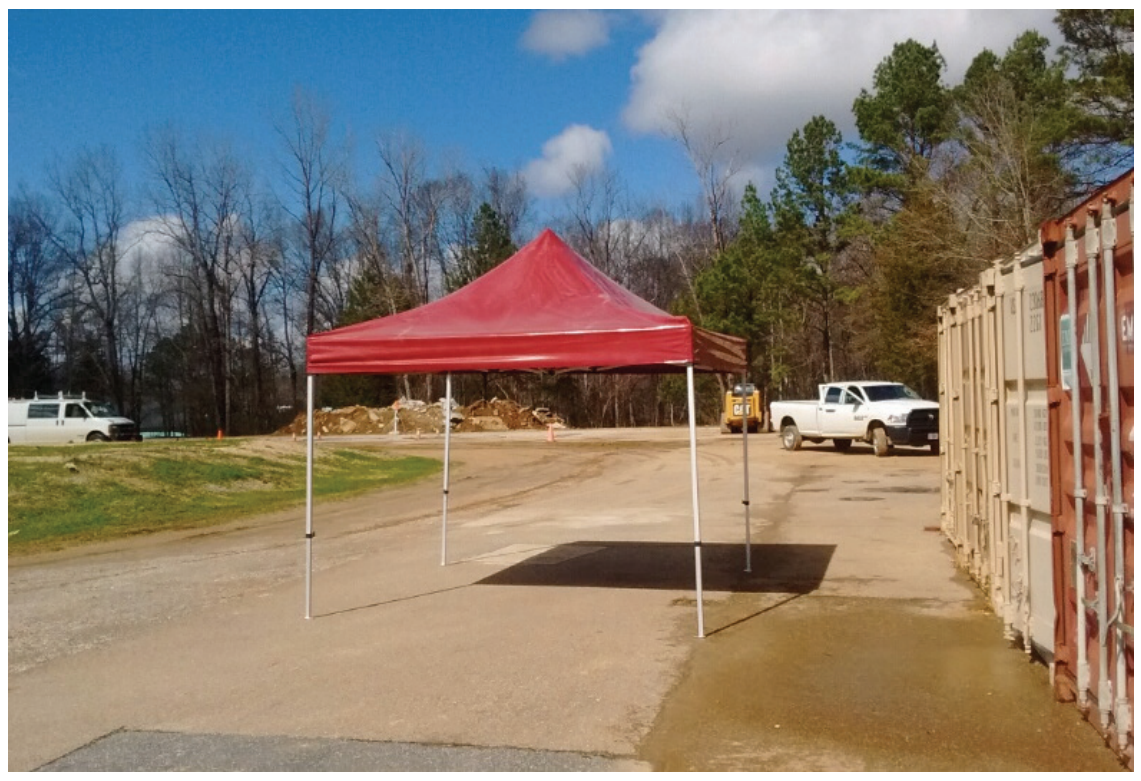


Figure 21. Nylon tent anchor bags.

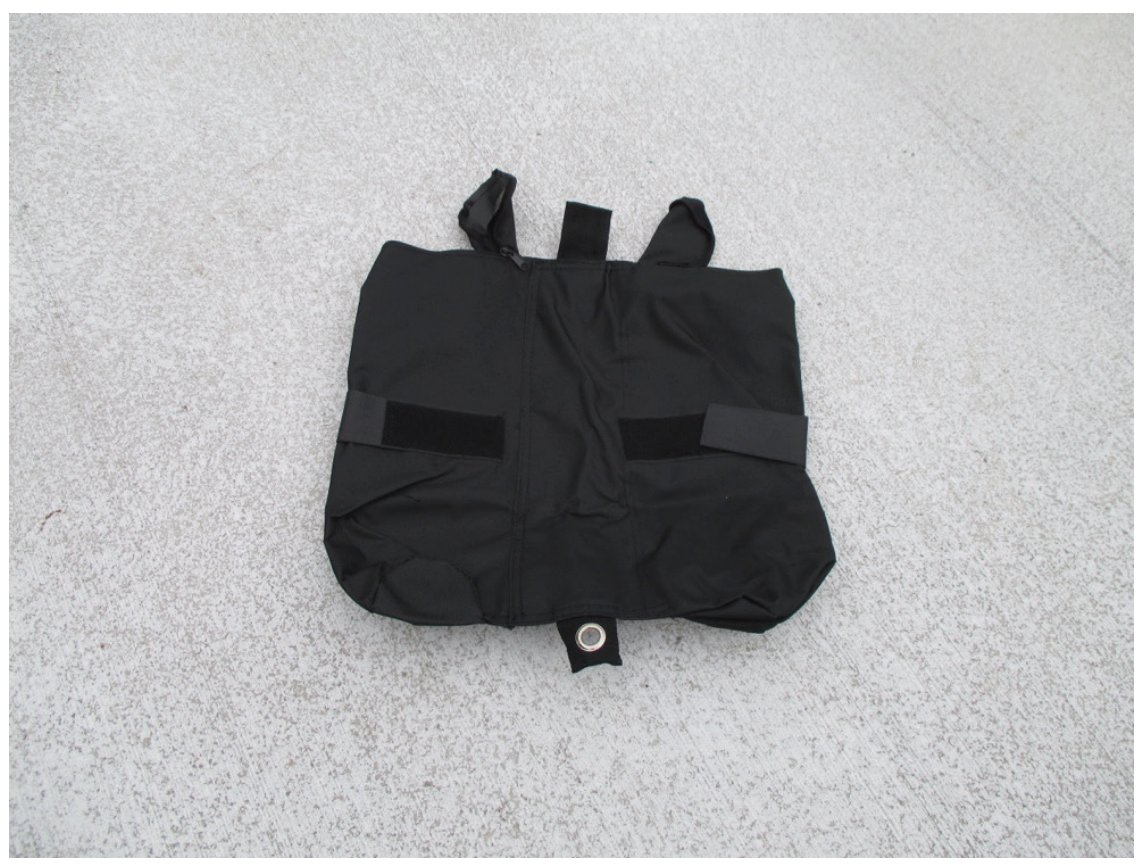

The water trash pump (Item 20), suction hose (Item 21), and discharge hose (Item 22) are used for pumping standing water out of the open repair area. The water pump and suction hose are secured on cantilever mounting arms (Item 38) installed on the wall of one of the containers. The suction hose strainer (Item 48) helps to ensure that large items, such as pieces of concrete or aggregate, are filtered to protect the equipment. Figure 22 shows the water pump with the hoses and the strainer installed.

Figure 23 shows one of the three Husqvarna backpack leaf blowers (Item 11) included in the prototype kit. The backpack leaf blower is used to remove standing water from the backfill surface immediately prior to capping the repairs. The wet/dry Shop-Vac vacuum (Item 10) shown in Figure 24 can also be used for extracting water from the repairs. Figure 24 also shows the accessories that come with the vacuum. The backpack leaf blowers are hung by custom short hangers (Item 39) on the wall of one of the containers, and the vacuum is hung by a custom long hanger (Item 33) on the wall of one of the containers. 
Figure 22. Water trash pump, discharge hose, suction hose, and strainer.

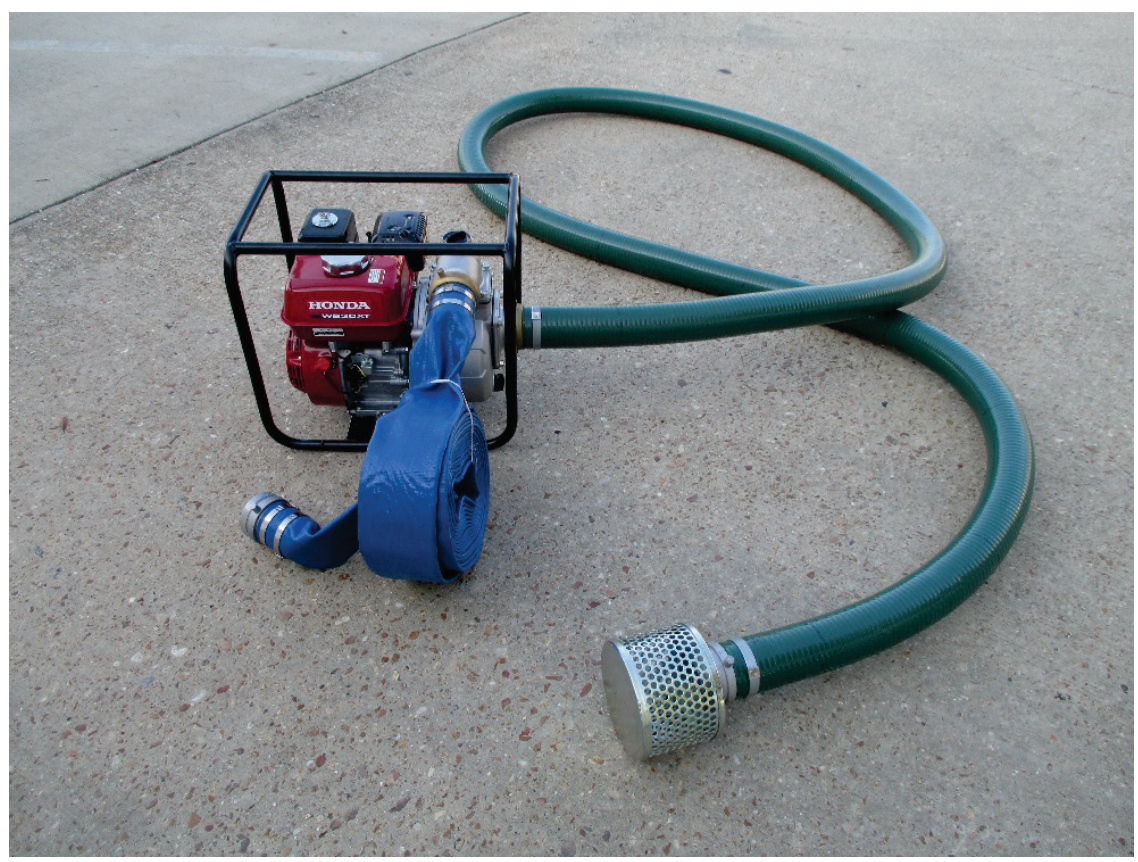

Figure 23. Backpack leaf blower with extendable arm accessories.

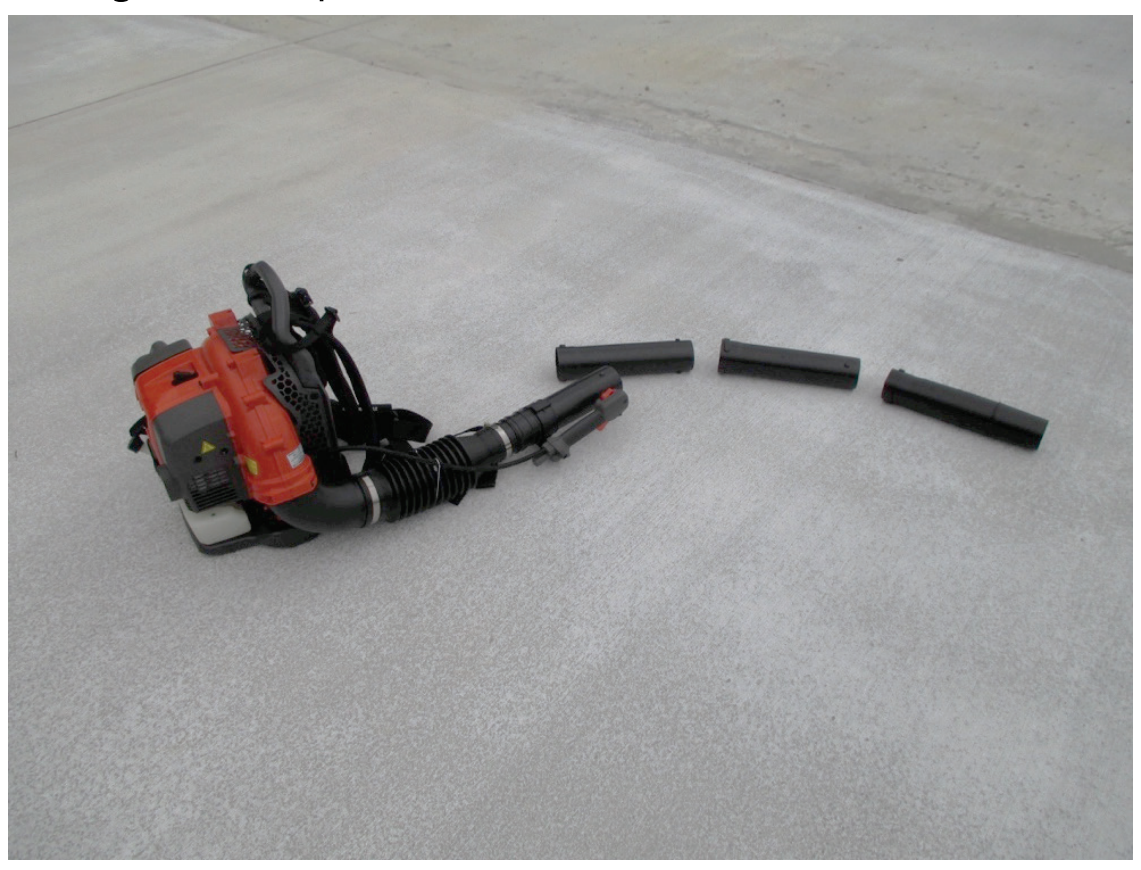


Figure 24. Wet/dry Shop-Vac vacuum and accessories.

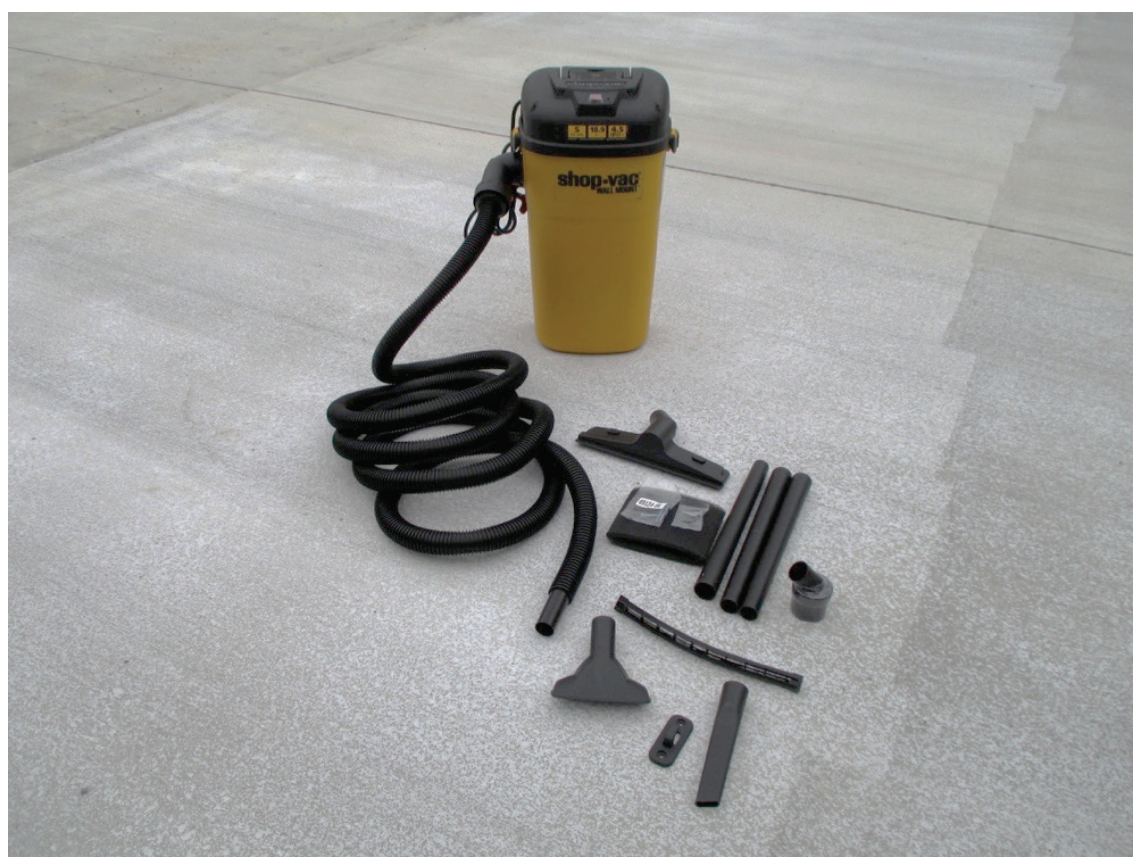

Coated vinyl tarps (Item 9), such as the one shown in Figure 25, are used to protect the backfill surface from rainfall after placement while waiting for capping to begin. They are also used to cover and protect the asphalt caps while compaction is taking place. The 16 - by 20 - $\mathrm{ft}$ tarps will not melt when placed over the hot asphalt surface during compaction and curing.

Figure 25. Vinyl tarps.

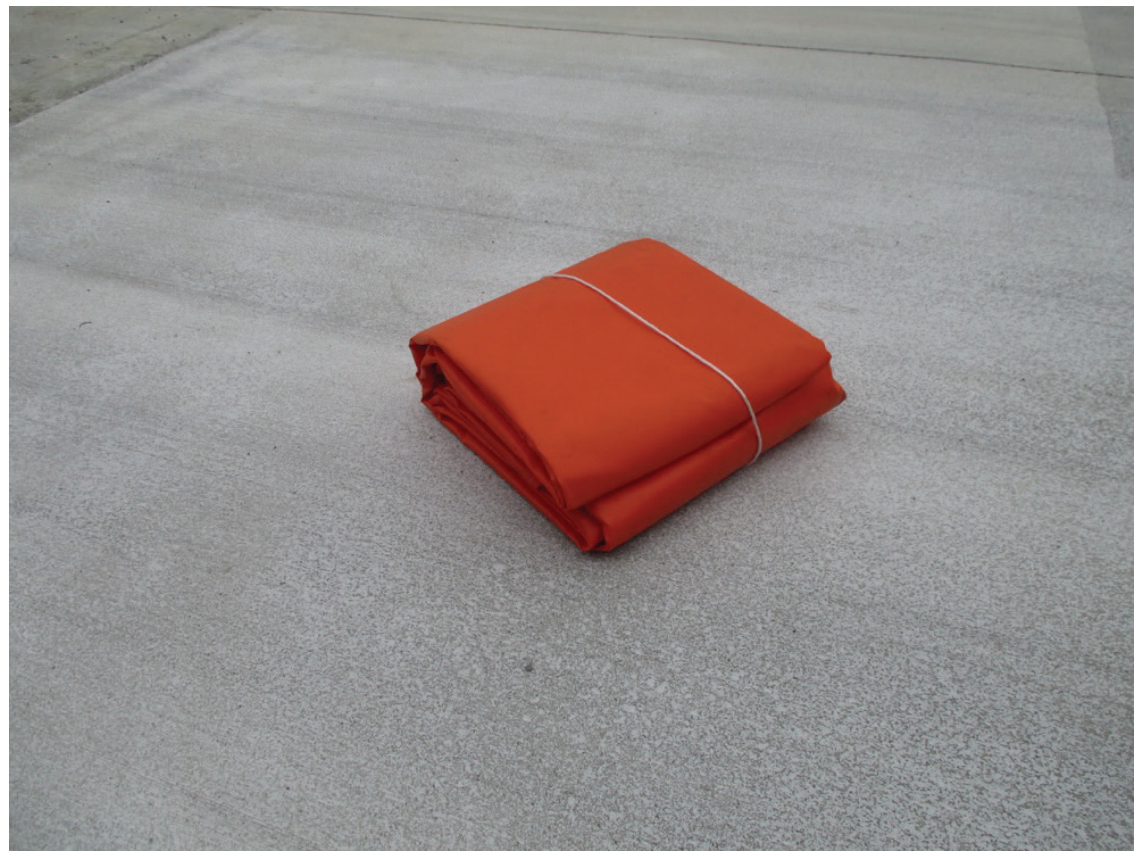


Black 6-mil polyethylene sheeting (Item 8 ) in 20 - by $100-\mathrm{ft}$ rolls is included in the kit because it may be necessary for placement over the freshly capped repairs to help trap some of the heat needed for proper curing of the rapid-setting concrete during low temperatures. Figure 26 shows one of the 20 - by $100-\mathrm{ft}$ rolls of the plastic sheeting.

Figure 26. Polyethylene sheeting.

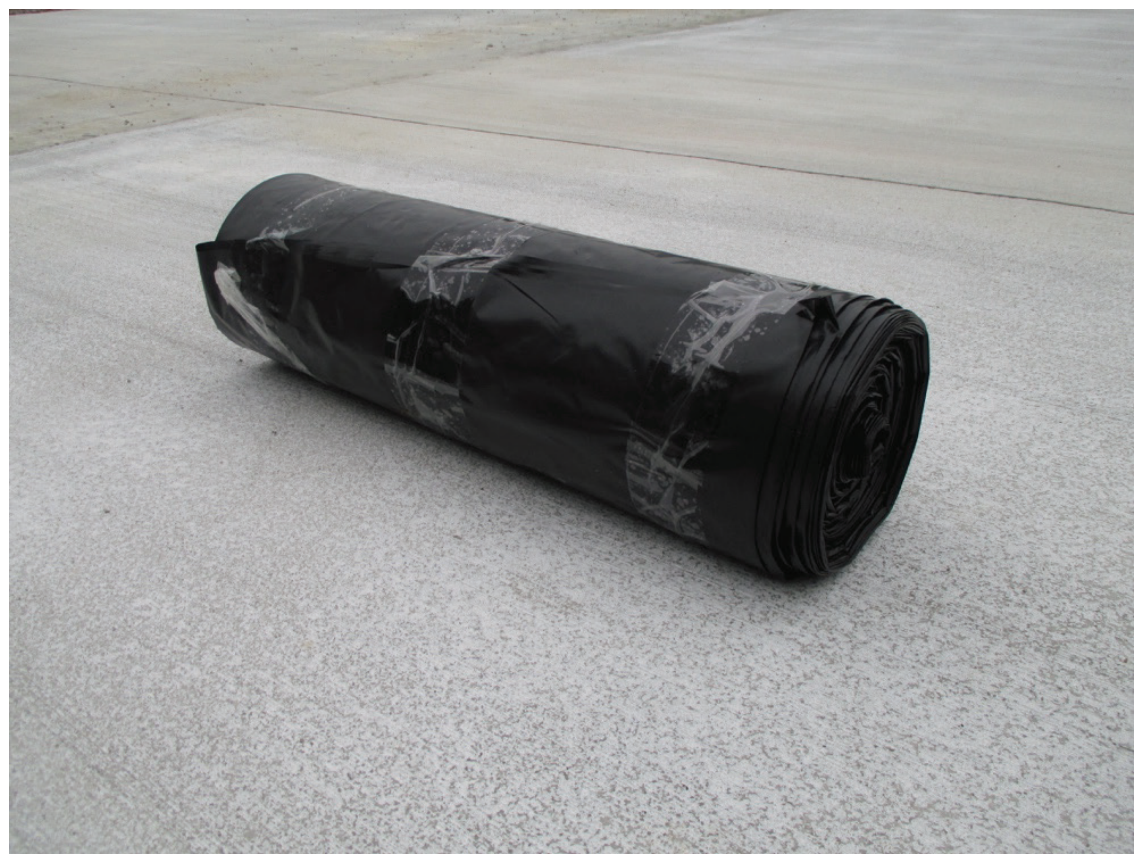

The 18- and 30-ft-long electric heating cables (Items 17 and 16, respectively) are used to cover the water lines of the simplified volumetric mixer during capping when the air temperatures are at or below freezing. They may also be used to protect the water pump on the mixer. Figure 27 shows the front and back package of the 30 -ft-long water pipe heat cable.

Figure 27. 30-ft-long electric water pipe heat cable.

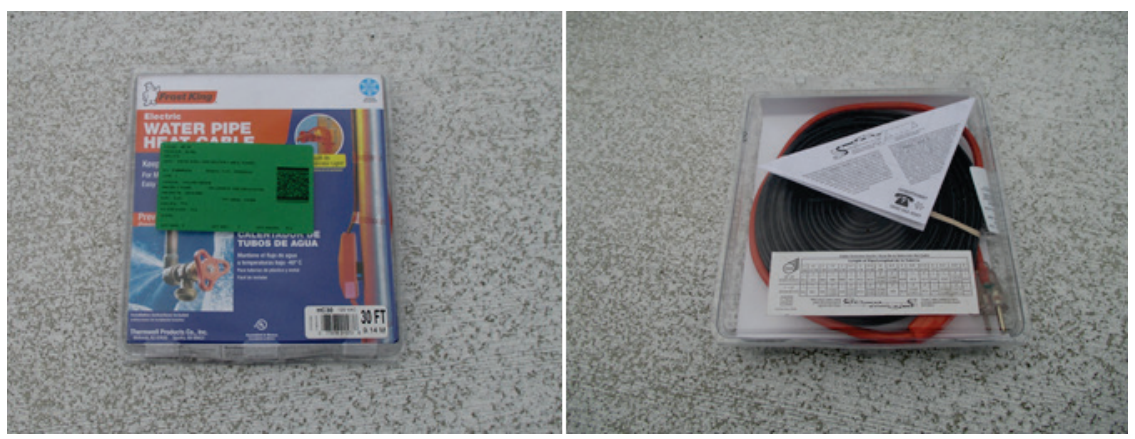


The in-line water heater (Item 19) is another item used for crater repair during cold weather. The heater (Figure 28) rapidly heats water from a local source as it is loaded into the mix tanks of the simplified volumetric mixer. A 3 -ft-long by 2.5 -ft-wide metal ramp (Item 27) is included and mounted on the inside door of one of the containers for loading and unloading the 330-lb inline water heater into and out of the container. The ramp is mounted using a custom manufactured ramp hangar (Item 28). Figure 29 shows the ramp in use. A 4-in.-long and 0.75-in.-wide aluminum stop (Item 44) is installed on the floor and in front of the heater to keep the heater from shifting inside the container during transit.

Each container is equipped with safety signs, as shown in Figure 30. The signs are included to remind the users to exercise caution when opening or working around the containers and to protect the users from harm due to the potential issues with residual fuel used in some of the tools included in the kit.

Figure 28. In-line water heater.

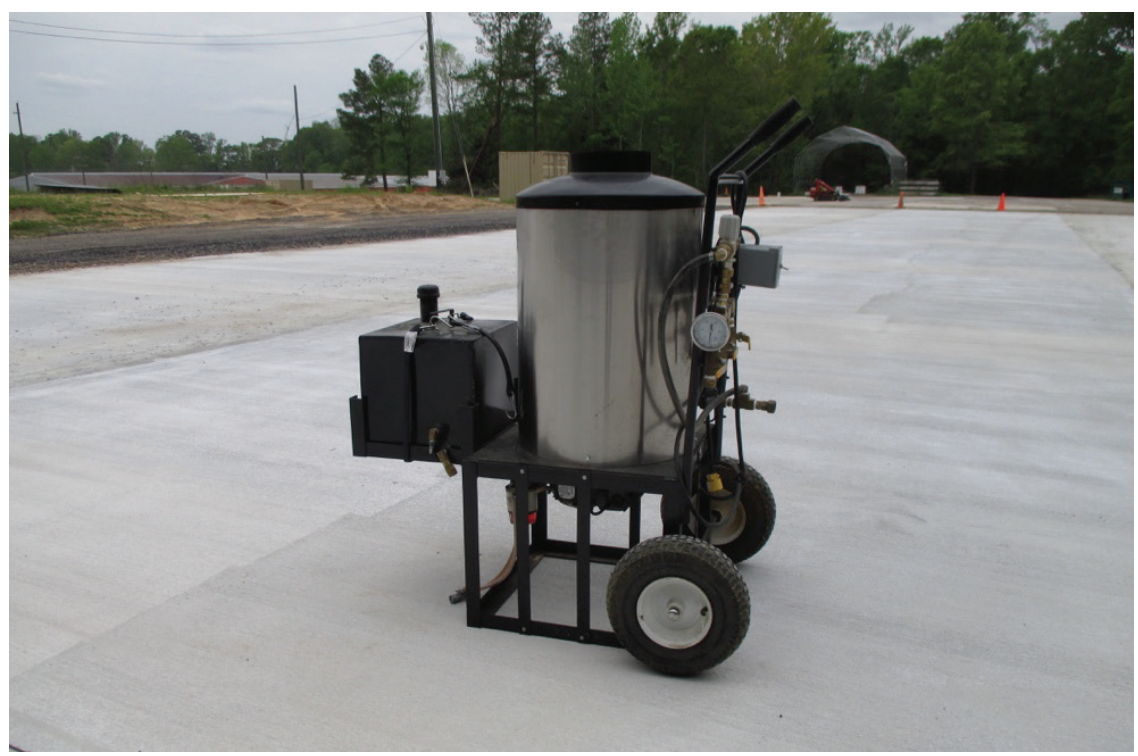


Figure 29. Unloading in-line water heater using metal ramp.

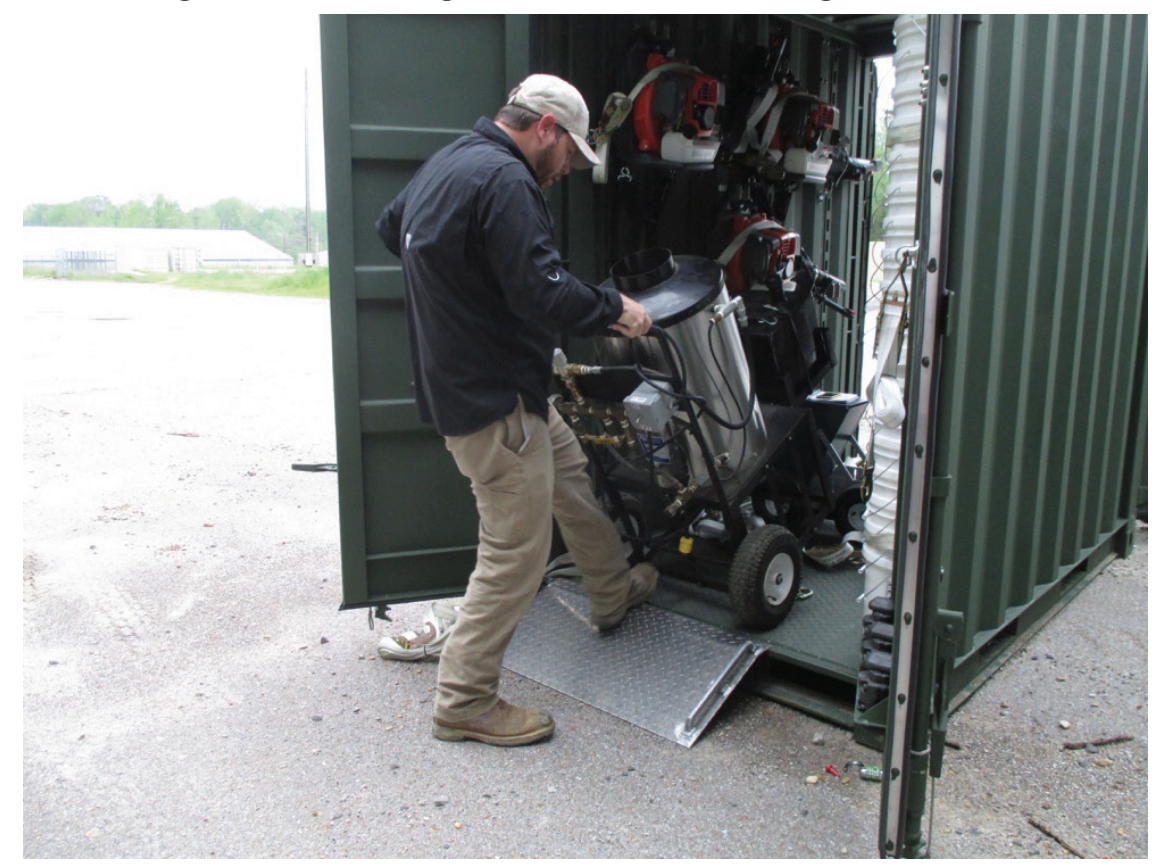

Figure 30. Warning and danger signs adhered to container doors.

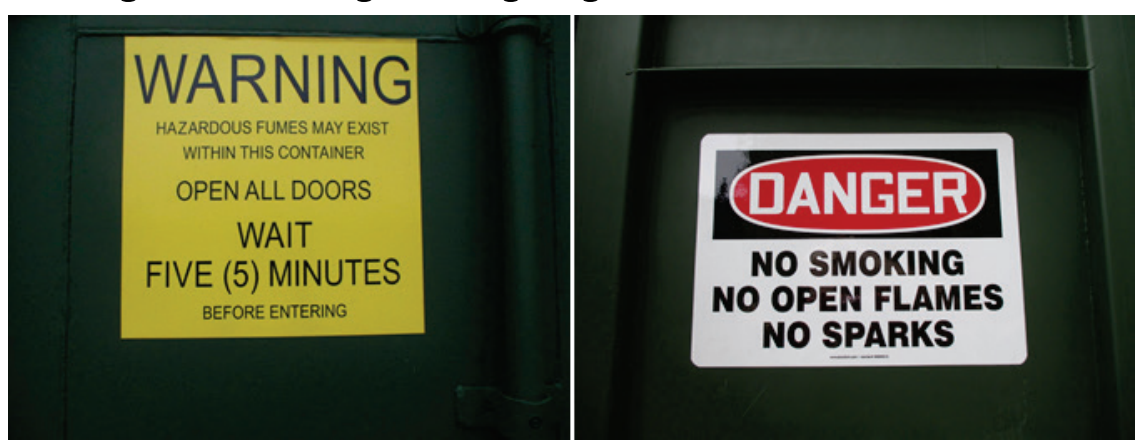




\section{Conclusions}

This report presents a summary of two full-scale crater repair experiments: (1) crater repair tests conducted in wet weather and (2) crater repair tests conducted in cold weather. The results of the full-scale tests led to the development of the prototype Inclement Weather Crater Repair Tool Kit, which was developed to supplement the ADR Tool Trailer during times of cold or wet weather. This report also includes the details of the tools, supplies, and equipment that were selected and packaged in the prototype Inclement Weather Crater Repair Tool Kit.

Critical items needed to mitigate the potential for adverse impact of rainfall during the crater repair process include

- Wet/dry-line marker,

- 30-ft-long fire hose with dust caps and dust plugs,

- 10-ft-long water containment dikes,

- No. 10 sieves,

- $16-\mathrm{ft}$ by 20 -ft coated vinyl tarps,

- Wet/dry vacuum,

- Backpack leaf blowers,

- 5-gal buckets with lids,

- 10-ft by 10-ft pop-up tents,

- Paint crayons,

- Tent anchor bags,

- Water trash pump with suction and discharge hoses and strainer, and

- Hand scoop.

Critical items needed for repairing craters in cold weather include

- $20-\mathrm{ft}$ by $100-\mathrm{ft}$ plastic sheeting,

- 30-ft-long electric pipe heat cable,

- 18 -ft-long electric pipe heat cable, and

- In-line water heater. 


\section{References}

Bell, H. P., L. Edwards, W. D. Carruth, J. S. Tingle, and J. R. Griffin. 2013. Wet weather crater repair testing at Silver Flag Exercise Site, Tyndall Air Force Base, Florida. ERDC/GSL TR-13-42. Vicksburg, MS: U.S. Army Engineer Research and Development Center.

Edwards, L., H. P. Bell, W. D. Carruth, J. R. Griffin, and J. S. Tingle. 2013. Cold weather crater repair testing at Malmstrom Air Force Base, Montana. ERDC/GSL TR13-32. Vicksburg, MS: U.S. Army Engineer Research and Development Center.

Pullen, A., C. Jackson, and B. Cotter. 2014. 2013 wet weather HMA crater repair technology demonstration. AFCEC-CX-TY-TR-2014-0026. Panama City, FL: Applied Research Associates. 


\section{Appendix: Inclement Weather ADR Crater Repair Prototype Tool Kit Design Drawings}




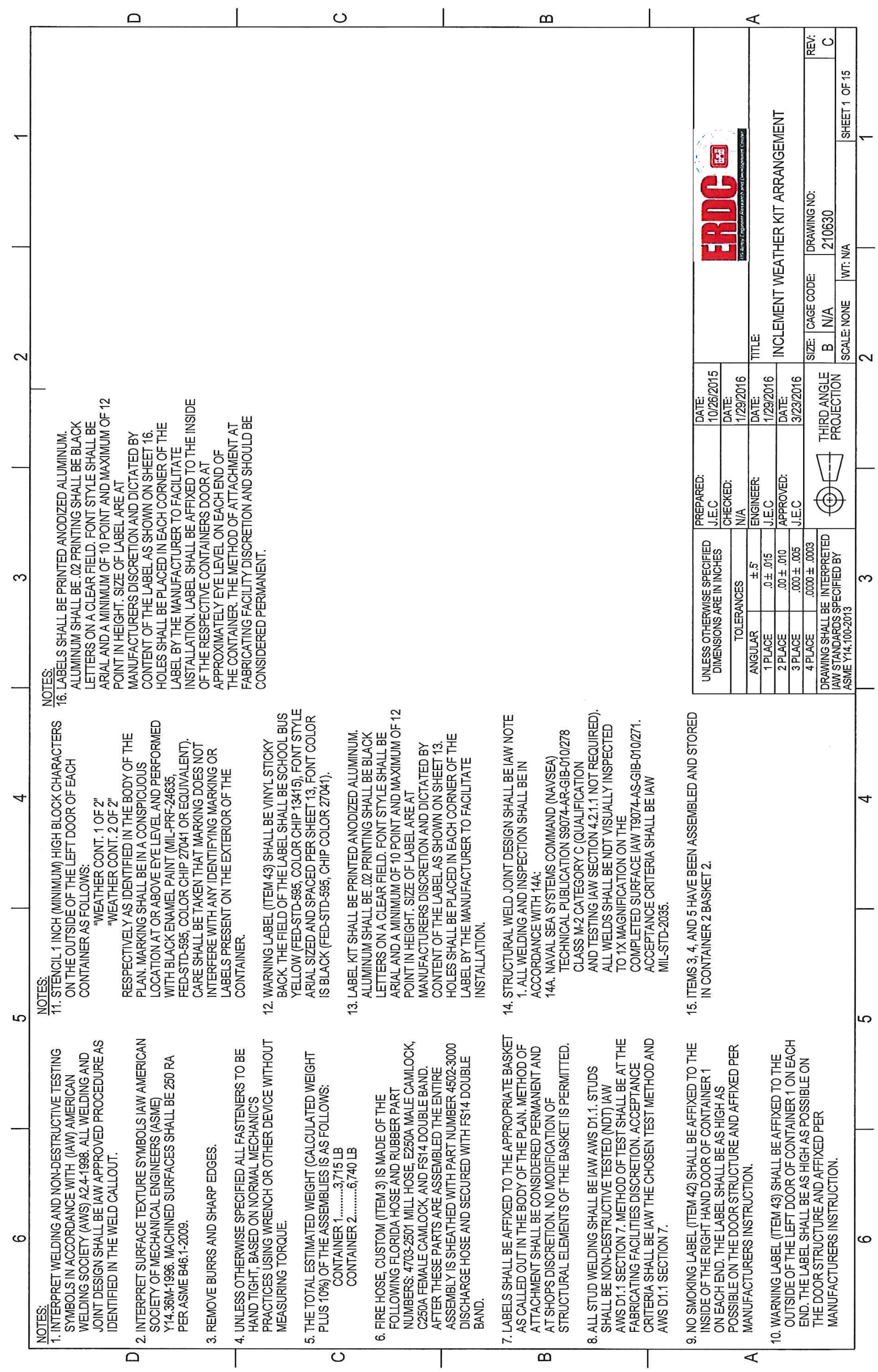




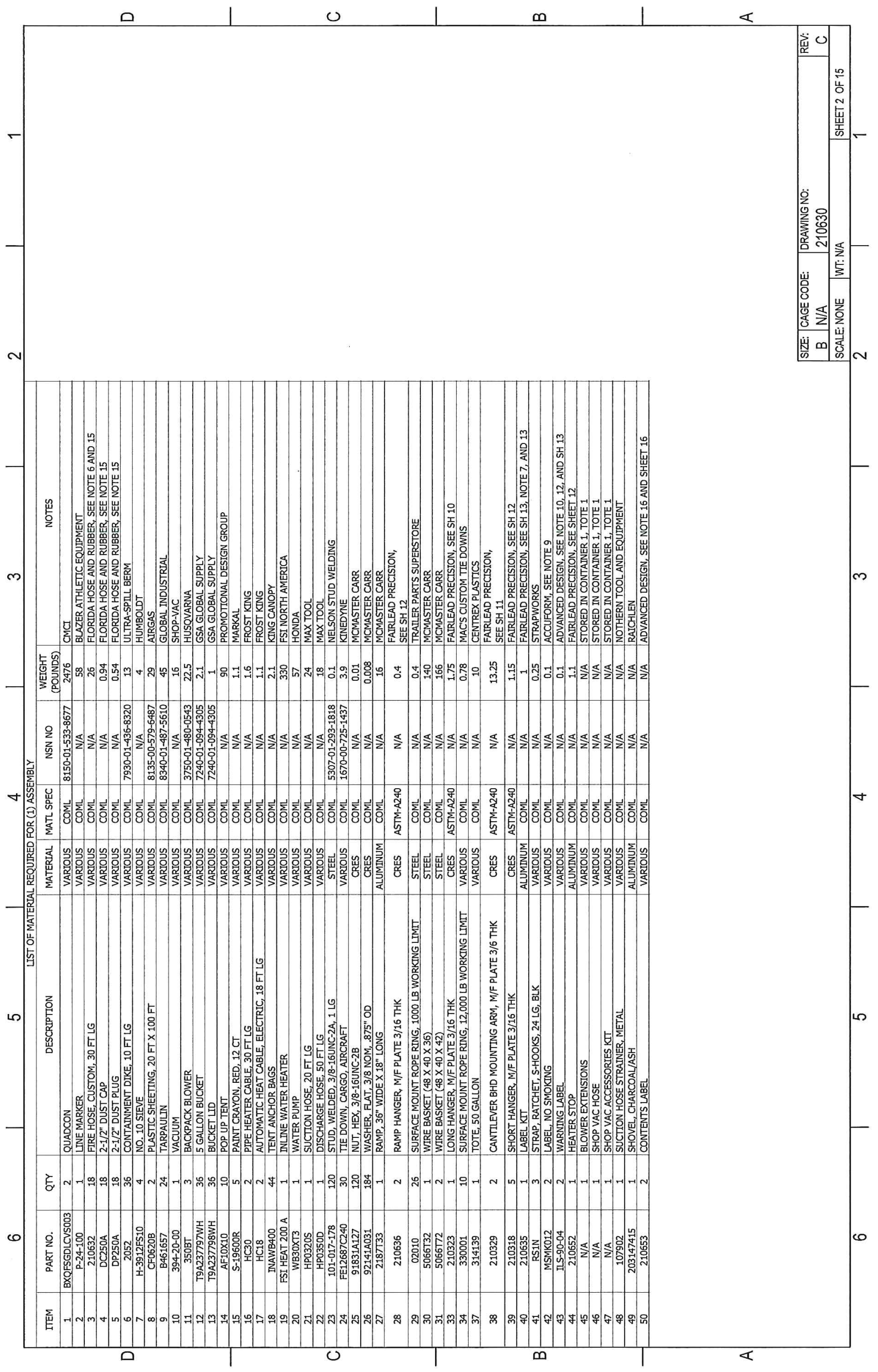




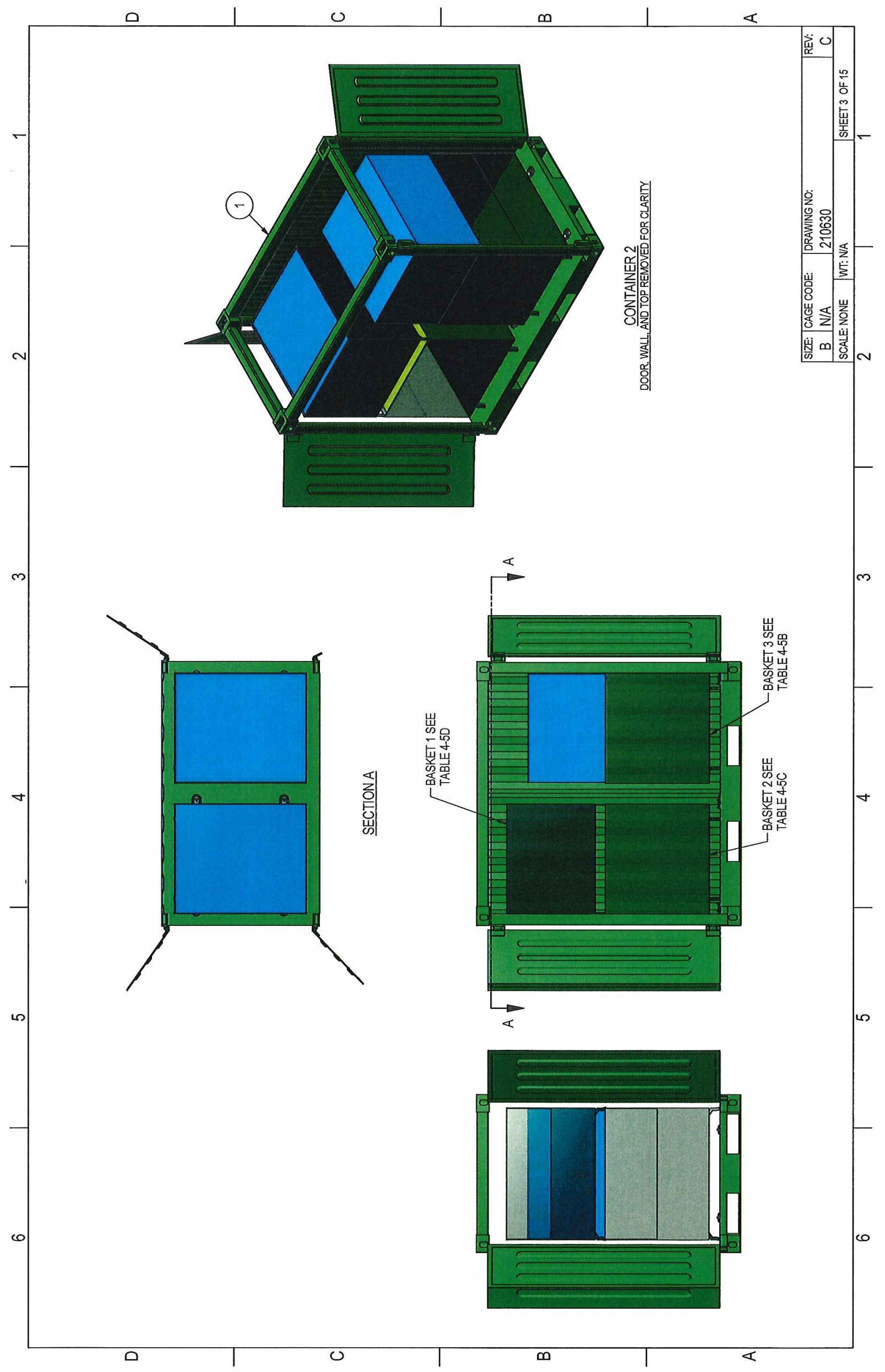




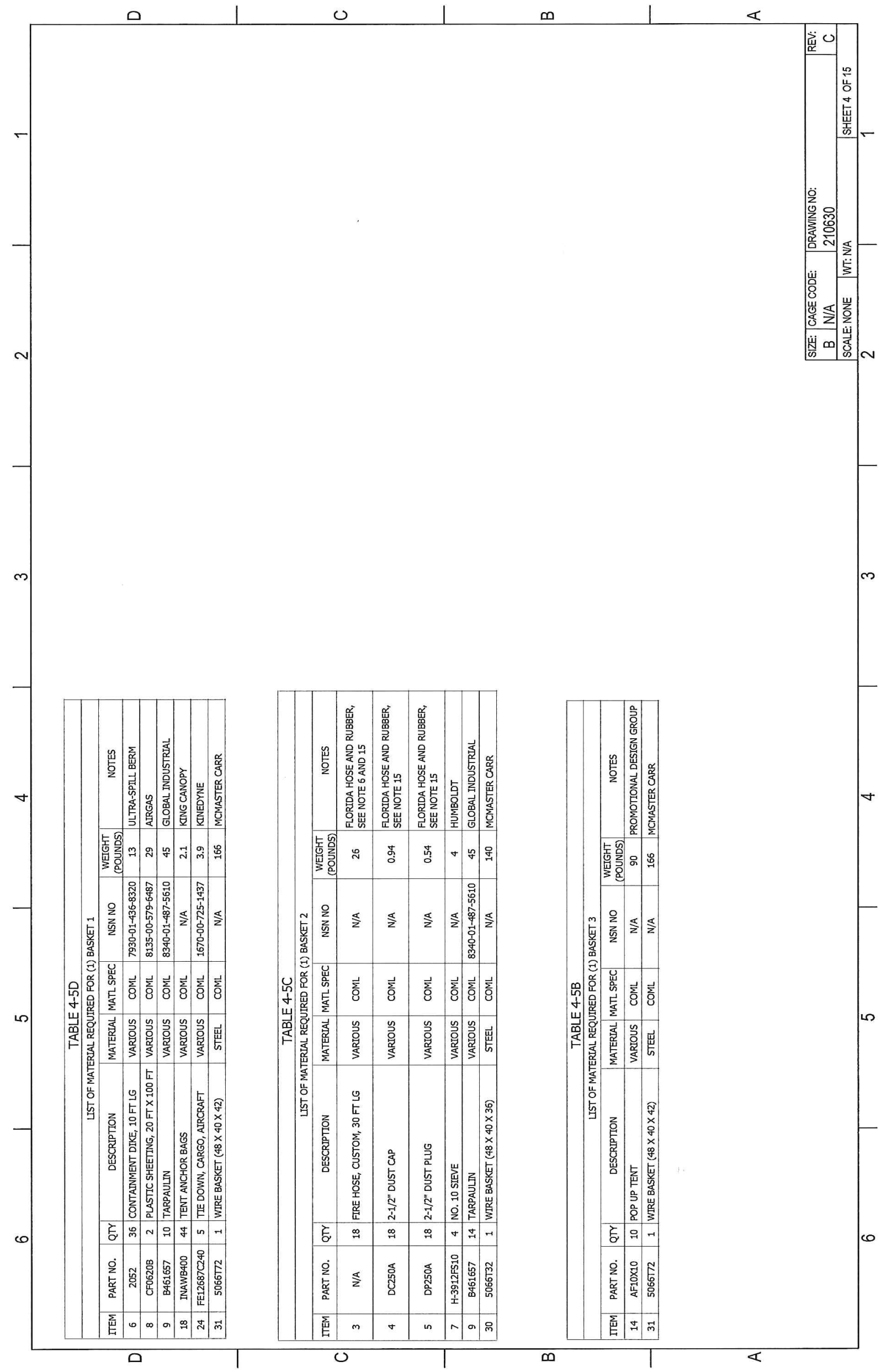




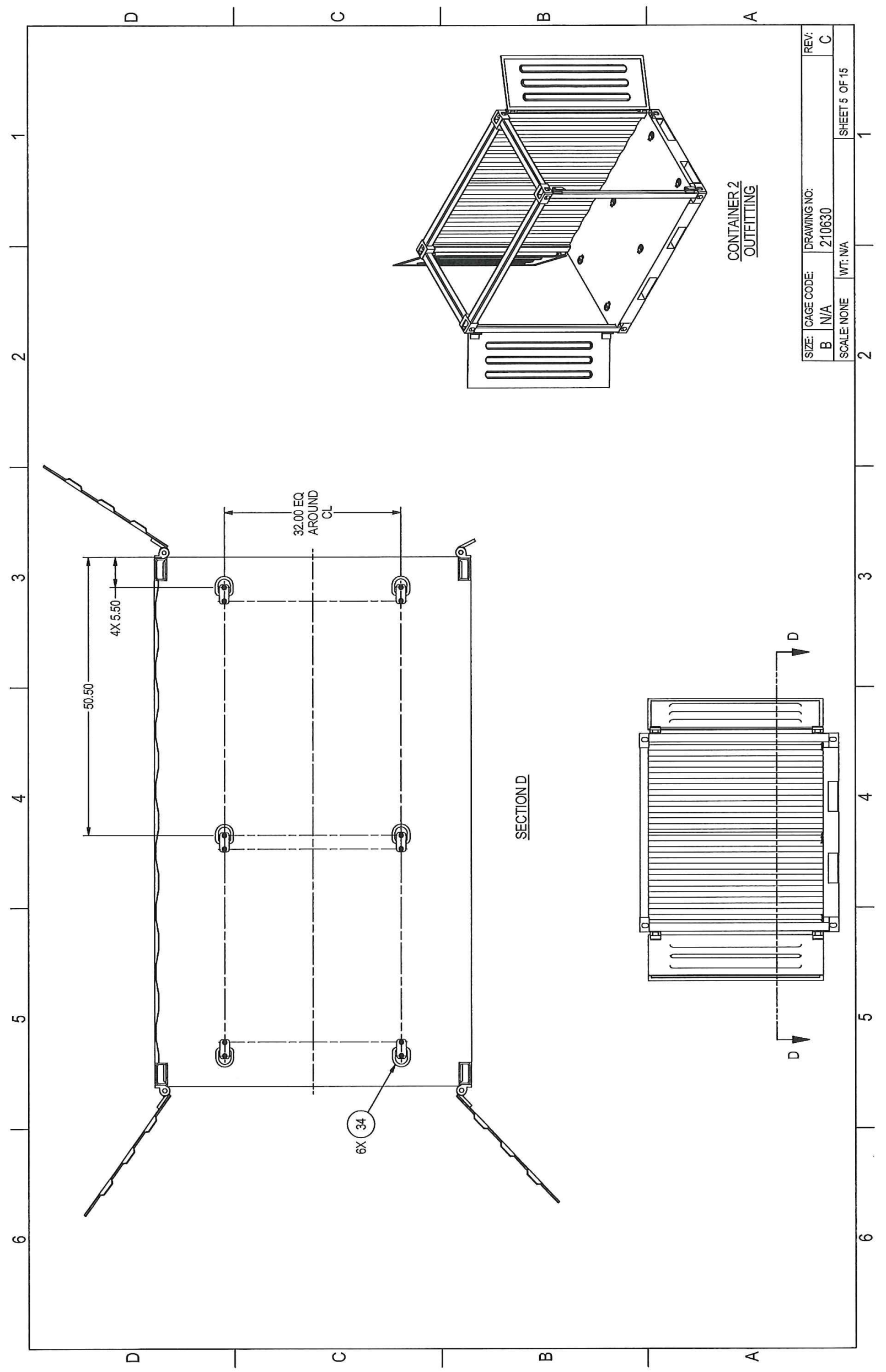




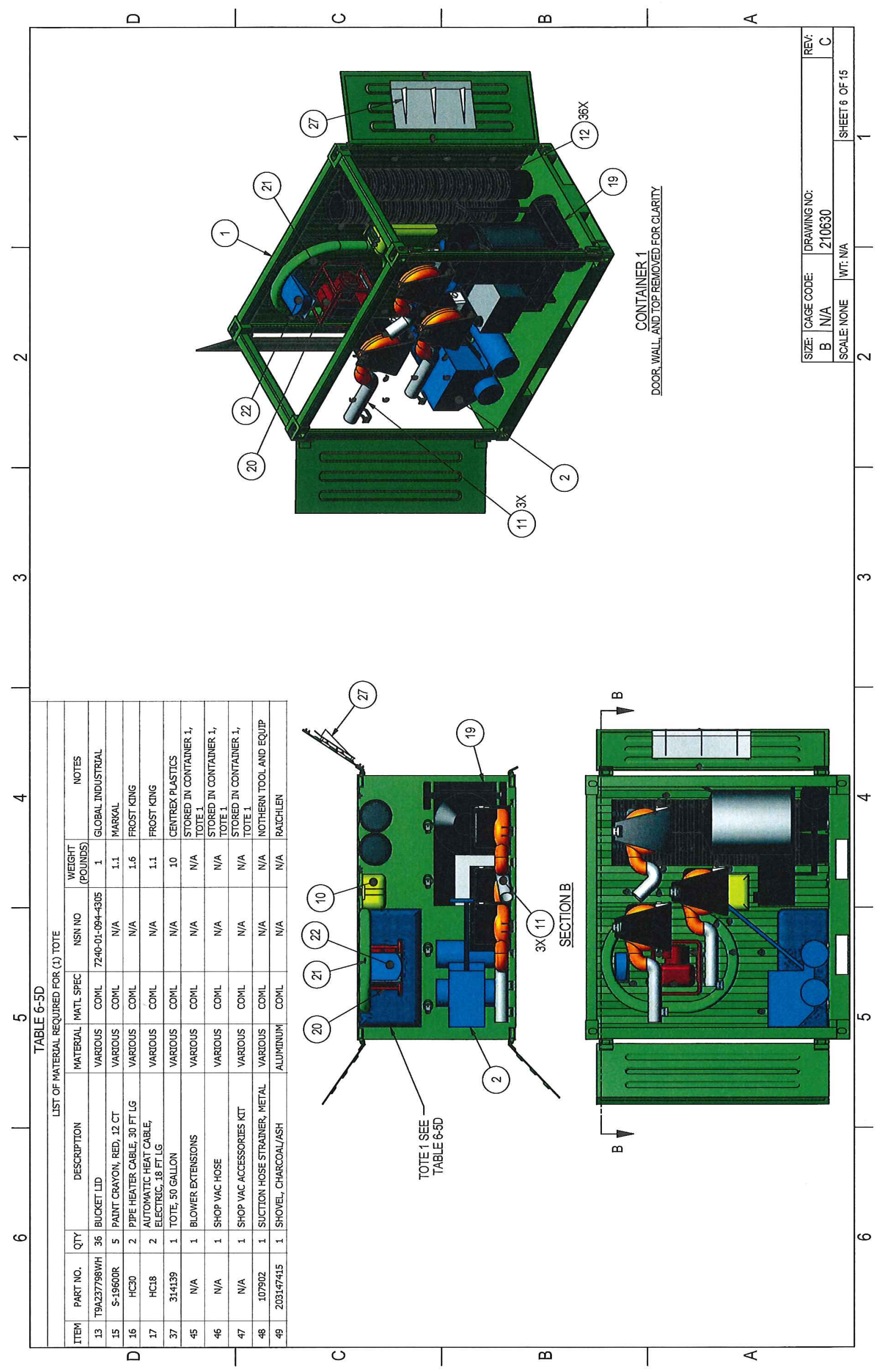




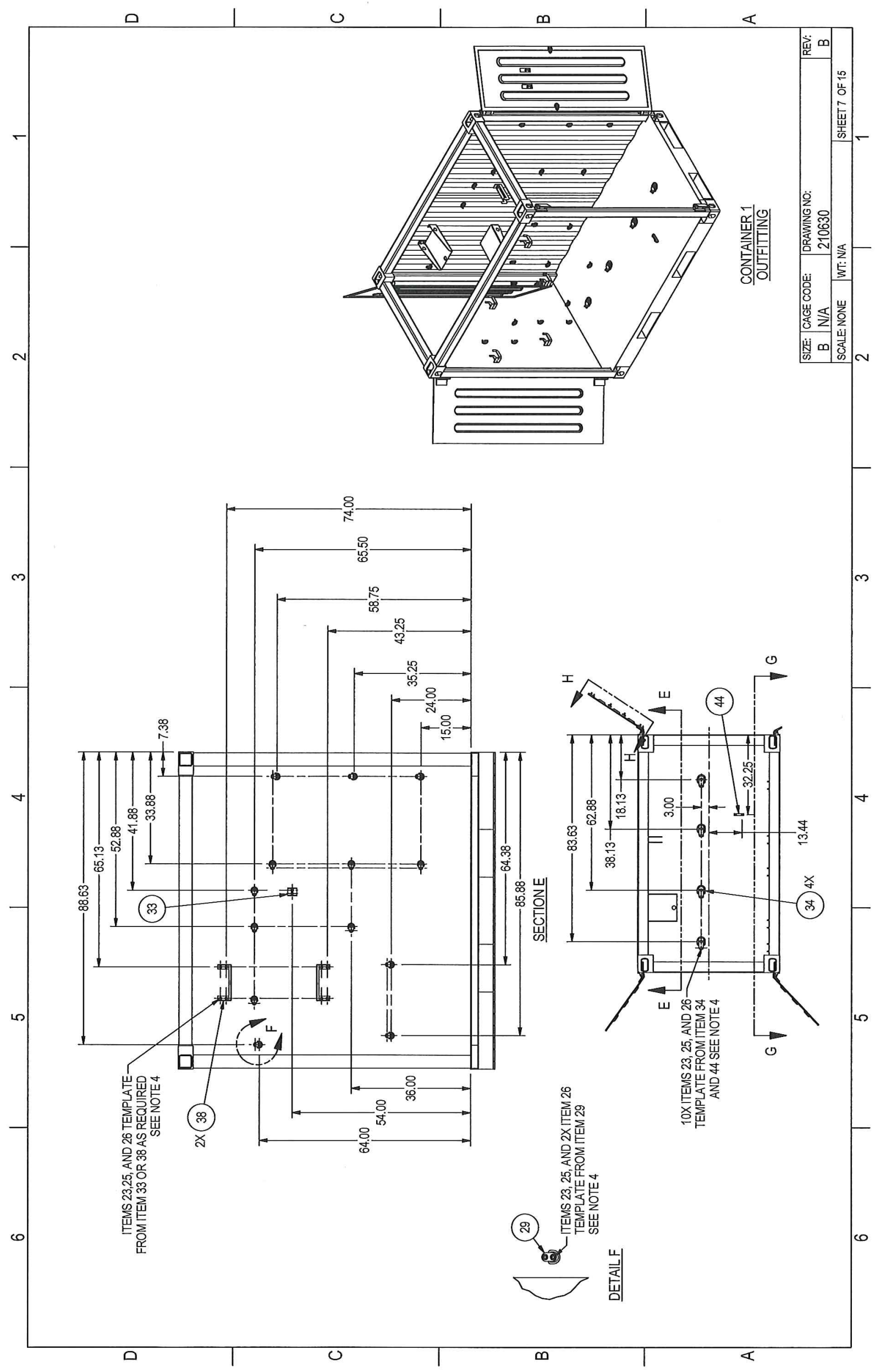




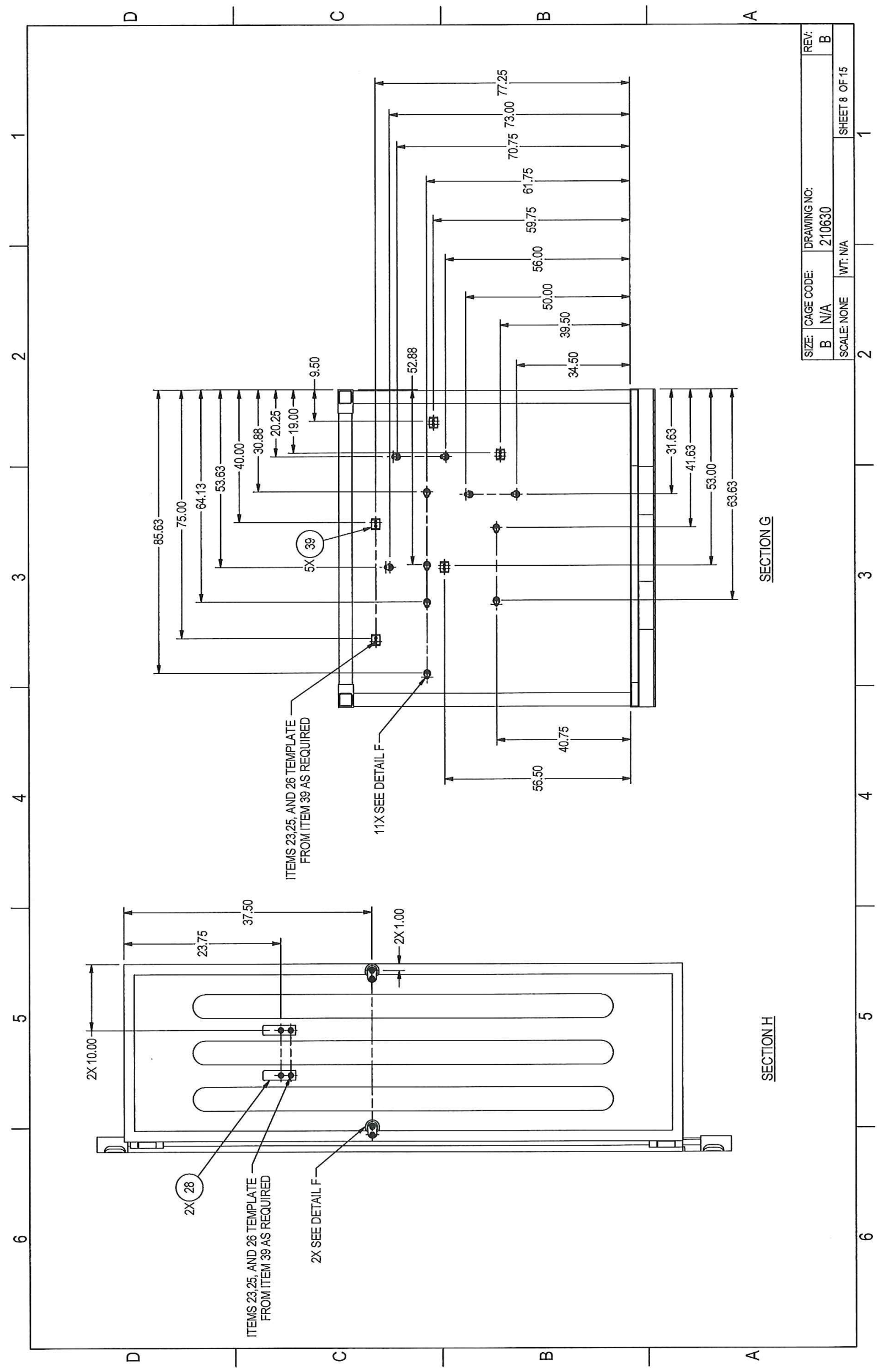




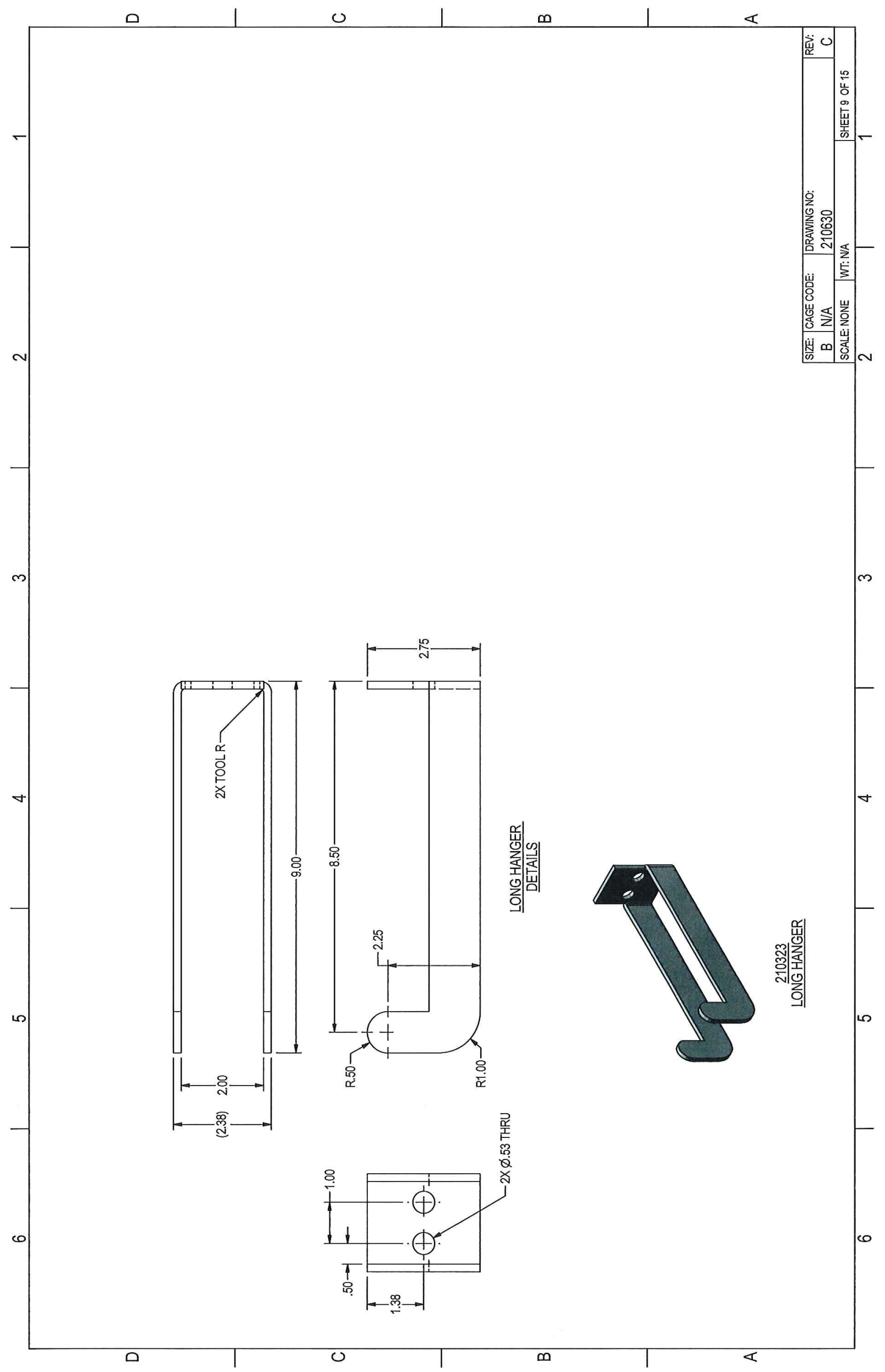




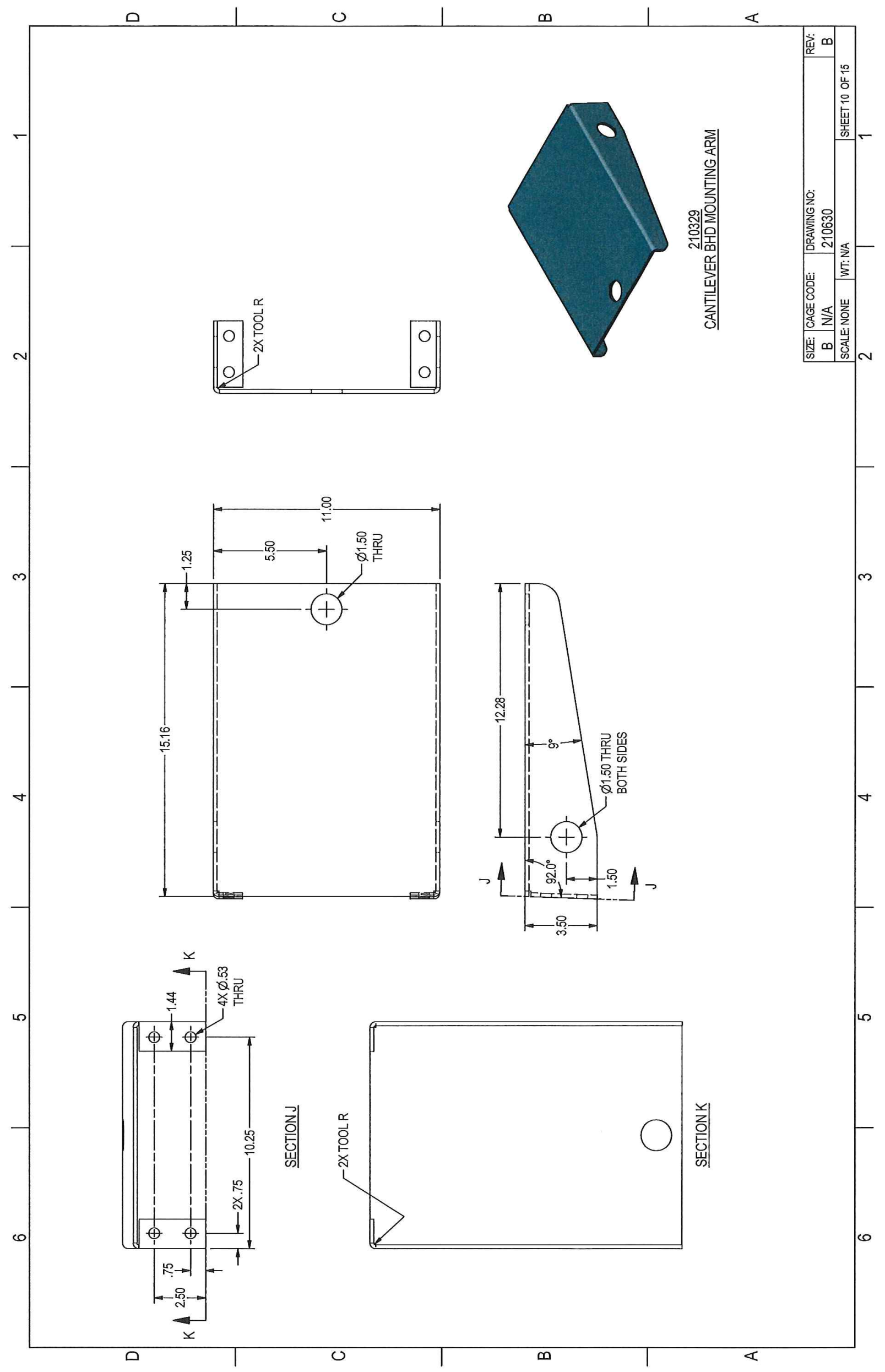




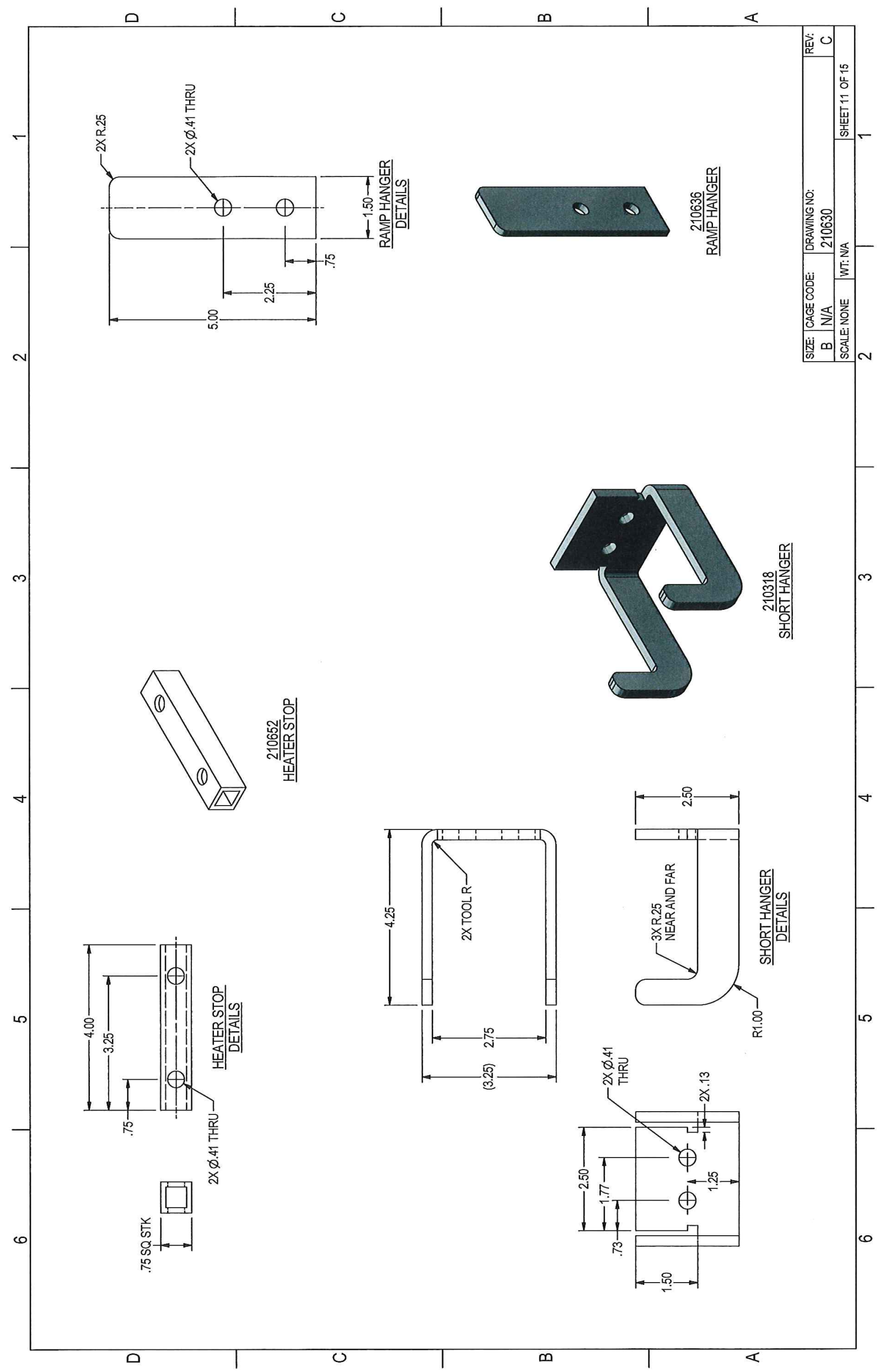




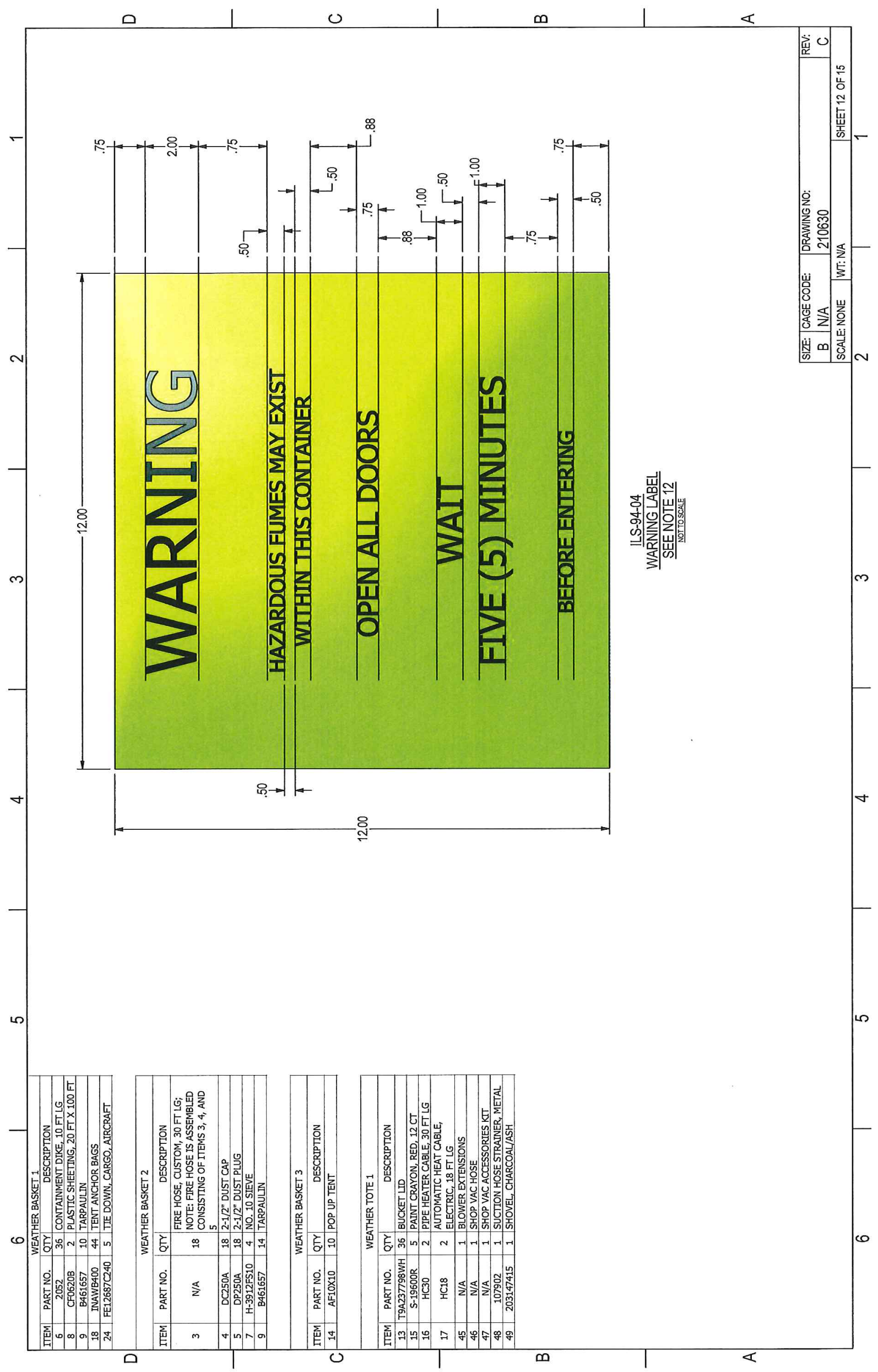




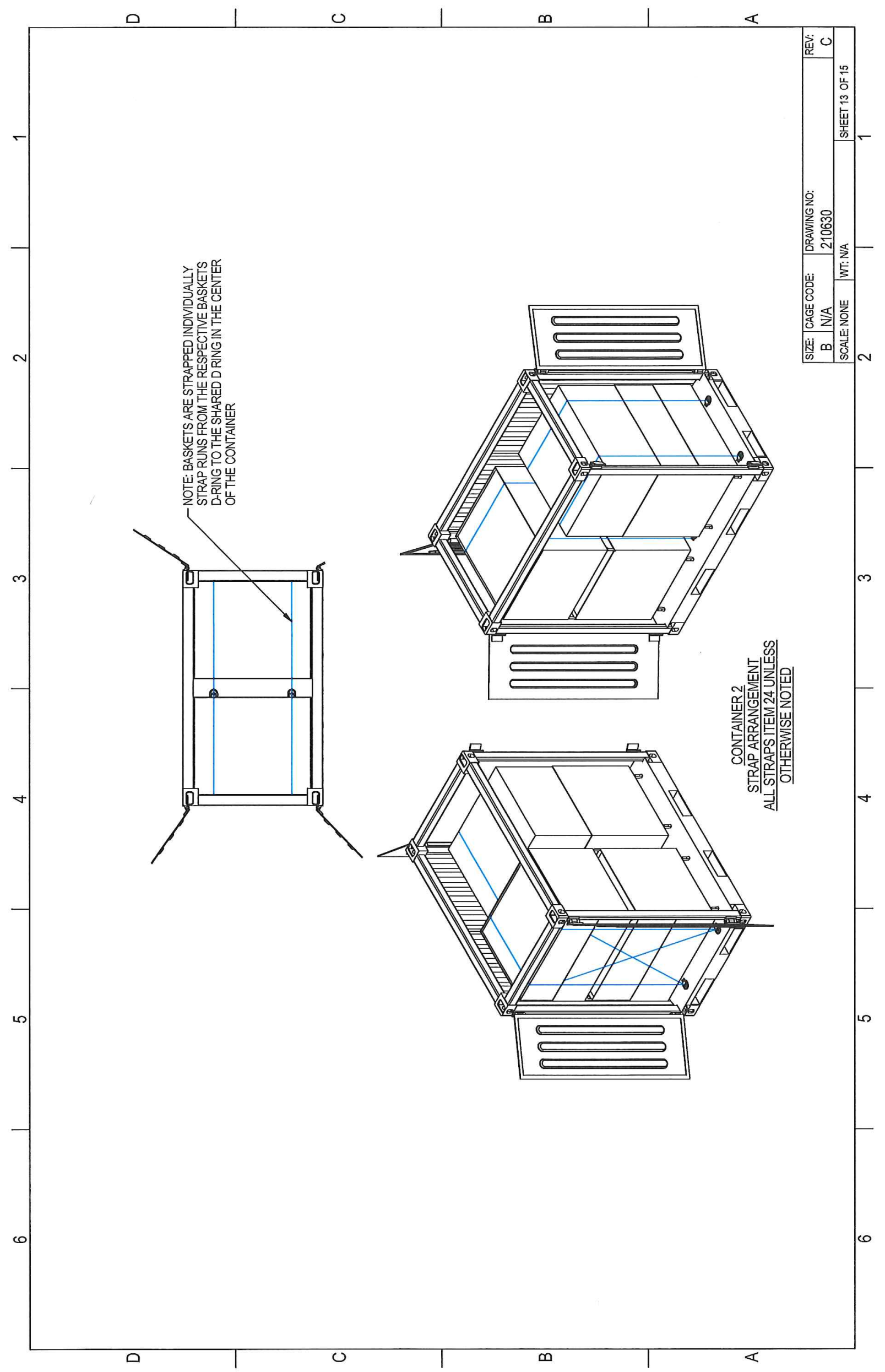




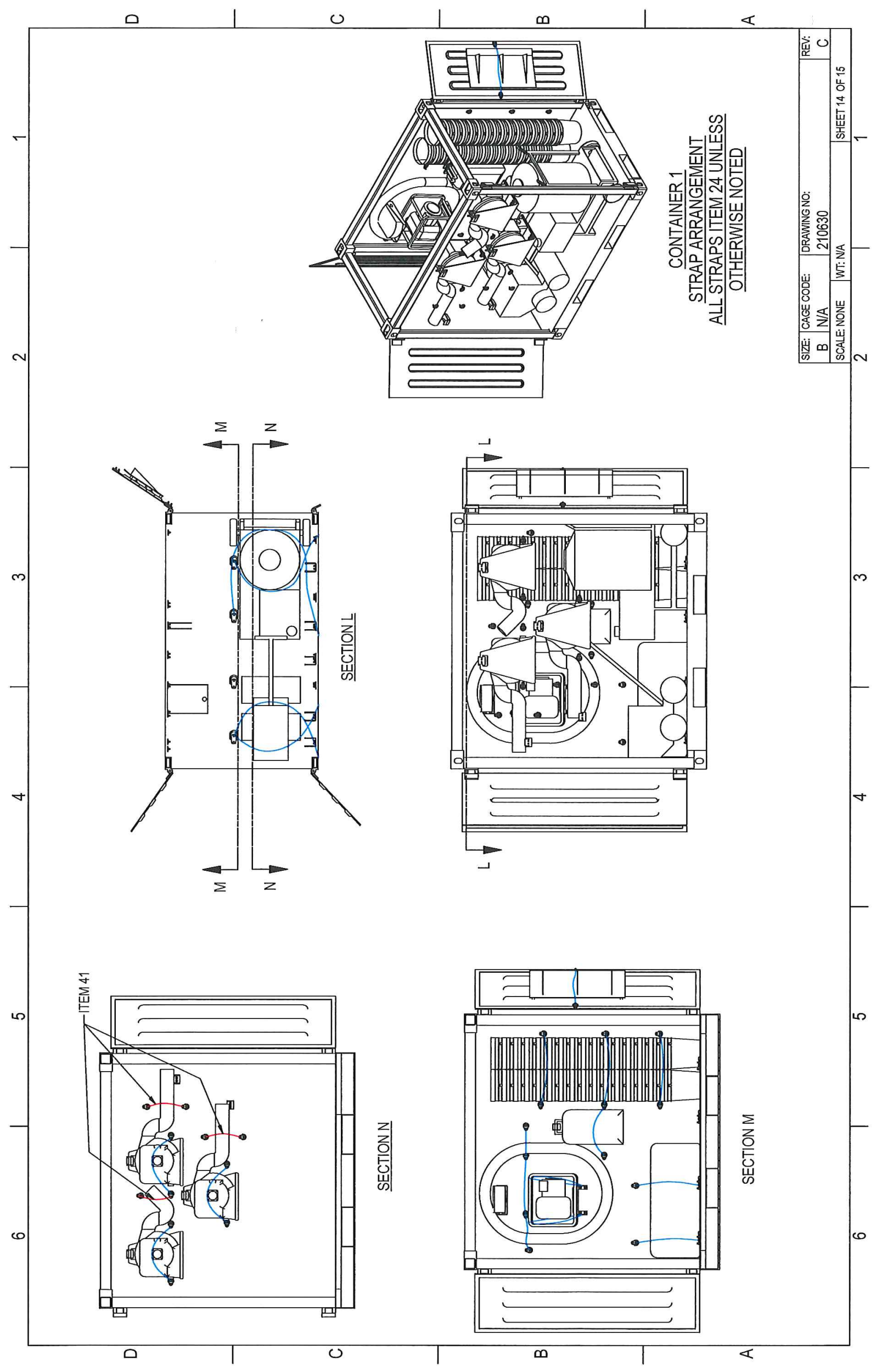




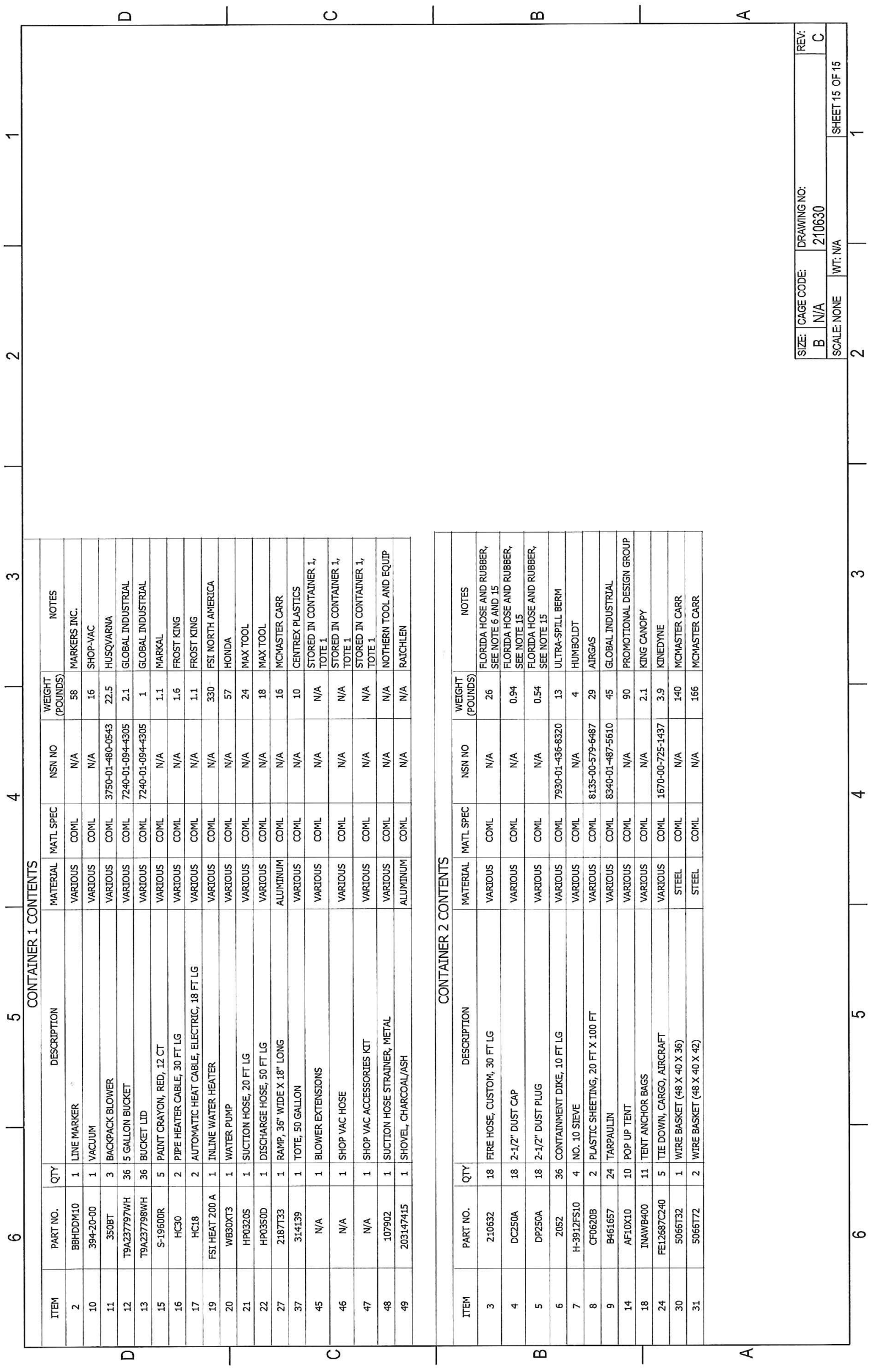




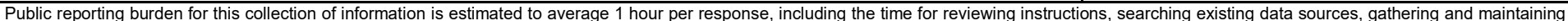

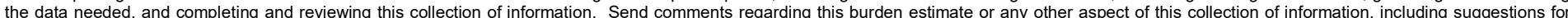

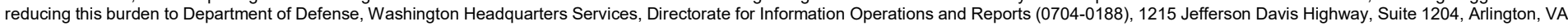

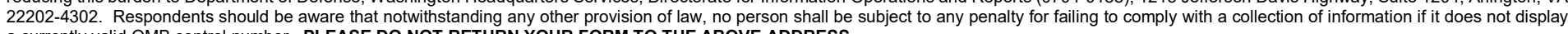
a currently valid OMB control number. PLEASE DO NOT RETURN YOUR FORM TO THE ABOVE ADDRESS.
1. REPORT DATE (DD-MM-YYYY) 2. REPORT TYPE
3. DATES COVERED (From - To)

November 2017 Final

\section{TITLE AND SUBTITLE}

Inclement Weather Crater Repair Tool Kit

5a. CONTRACT NUMBER

5b. GRANT NUMBER

5c. PROGRAM ELEMENT NUMBER

\section{AUTHOR(S)}

Haley P. Bell and Jeb S. Tingle

5d. PROJECT NUMBER

333159

5e. TASK NUMBER

5f. WORK UNIT NUMBER

\section{PERFORMING ORGANIZATION NAME(S) AND ADDRESS(ES)}

Geotechnical and Structures Laboratory

U.S. Army Engineer Research and Development Center

3909 Halls Ferry Road

Vicksburg, MS 39180-6199

\section{SPONSORING / MONITORING AGENCY NAME(S) AND ADDRESS(ES)}

Headquarters, U.S. Air Force Civil Engineer Center

Tyndall Air Force Base, FL 32403-5319

8. PERFORMING ORGANIZATION REPORT NUMBER

ERDC/GSL TR-17-26

10. SPONSOR/MONITOR'S ACRONYM(S)

AFCEC

11. SPONSOR/MONITOR'S REPORT NUMBER(S)

\section{DISTRIBUTION / AVAILABILITY STATEMENT}

Approved for public release; distribution is unlimited.

\section{SUPPLEMENTARY NOTES}

\section{ABSTRACT}

During the period October 2015 through May 2016, the U.S. Army Engineer Research and Development Center (ERDC) in Vicksburg, MS, worked to develop a prototype tool kit comprised of equipment and materials needed to repair concrete and asphalt craters on airfield pavements during times of inclement weather. The tool kit is used to supplement an existing crater repair tool kit developed for fair weather scenarios. The items selected for inclusion in the kit were based on previous research and evaluation of crater repair methods and during specific full-scale inclement weather crater repair experiments. This report presents a summary of the research conducted to help determine the prototype Inclement Weather Crater Repair Tool Kit contents and also presents the specific details of the kit, including inventory and drawings.

\section{SUBJECT TERMS}

Runways (Aeronautics) - maintenance and repair

Tools

Rain and rainfall
Airfield damage repair
Crater
Blast effect
Cold weather operation

\begin{tabular}{l}
\hline 16. SECURITY CLASSIFICATION OF: \\
\begin{tabular}{|c|c|c|}
\hline a. REPORT & b. ABSTRACT & c. THIS PAGE \\
Unclassified & Unclassified & Unclassified \\
\hline
\end{tabular}
\end{tabular}

17. LIMITATION
OF ABSTRACT

\section{NUMBER} OF PAGES

52
Inclement weather

Repair kit

Cratering 